\title{
Expanding global commodities trade and consumption place the world's primates at risk of extinction
}

\author{
Alejandro Estrada ${ }^{\text {Corresp., } 1}$, Paul A Garber ${ }^{\text {Corresp., } 2}$, Abhishek Chaudhary ${ }^{3}$ \\ ${ }^{1}$ National Autonomous University of Mexico, Institute of Biology, Mexico City, Mexico \\ 2 Department of Anthropology, University of Illinois at Urbana-Champaign, Urbana, Illinois, United States \\ 3 Department of Civil Engineering, Indian Institute of Technology (IIT), Kanpur, Kanpur, India \\ Corresponding Authors: Alejandro Estrada, Paul A Garber \\ Email address: aestradaprimates@gmail.com, p-garber@illinois.edu
}

As a consequence of recent human activities. populations of approximately $75 \%$ of the world's primates are in decline, and more than $60 \%$ of species $(n=512)$ are threatened with extinction. Major anthropogenic pressures on primate persistence include the widespread loss and degradation of natural habitats caused by the expansion of industrial agriculture, pastureland for cattle, logging, mining, and fossil fuel extraction. This is the result of growing global market demands for agricultural and non-agricultural commodities. Here we profile the effects of international trade of forest-risk agricultural and non-agricultural commodities, namely soybean, oil palm, natural rubber, beef, forestry products, fossil fuels, metals, minerals, and gemstones on habitat conversion in the Neotropics, Africa, and South and Southeast Asia. Total estimated forest loss for these regions between 2001 and 2017 was ca 179 million ha. The average percent of commodity-driven permanent deforestation for the period 2001-2015 was highest in Southeast Asia (47\%) followed by the Neotropics (26\%), South Asia (26\%) and Africa (7\%). Commodities exports increased significantly between 2000 and 2016 in all primate range regions leading to the widespread conversion of forested land to agricultural fields and an increase in natural resource extraction. In 2016, US \$1.1 trillion of natural-resource commodities were traded by countries in primate range regions. The Neotropics accounted for $41 \%$ of the total value of these exports, Southeast Asia for $27 \%$, Africa $21 \%$, and South Asia 11\%. Major commodity exporters in 2016 were Brazil, India, Indonesia, Malaysia and South Africa, countries of high primate diversity and endemism. Among the top 10 importers were China, the US, Japan, and Switzerland.Primate range countries lag far behind importer nations in food security and gross domestic product per capita, suggesting that trade and commodity-driven land-use have done little to generate wealth and well-being in primate habitat countries.Modeling of land-use and projected extinction of primate species by 2050 and 2100 under a business as usual scenario for 61 primate 
range countries indicate that each country is expected to see a significant increase in the number of species threatened with extinction.To mitigate this impending crisis, we advocate the "greening" of trade, a global shift towards a low-meat diet, reduced consumption of oil seed, diminished use of tropical timber, fossil fuels, metals, minerals and gemstones from the tropics, accompanied by a stronger and sustained global resolve to regulate and reverse the negative impacts of growing unsustainable global demands and commodity trade on income inequality, and the destruction of primates and their habitats. 


\section{Expanding global commodities trade and consumption place the world's}

\section{2 primates at risk of extinction}

4 Alejandro Estrada ${ }^{1}$, Paul A. Garber ${ }^{2}$, Abhishek Chaudhary $^{3}$

$6{ }^{1}$ Institute of Biology, National Autonomous University of Mexico (UNAM), Mexico City,

7 Mexico

8 2Department of Anthropology, University of Illinois at Urbana-Champaign, Urbana, IL, USA

$9{ }^{3}$ Department of Civil Engineering, Indian Institute of Technology (IIT) Kanpur, India

ABSTRACT

12 As a consequence of recent human activities. populations of approximately $75 \%$ of the world's primates

13 are in decline, and more than $60 \%$ of species $(n=512)$ are threatened with extinction. Major

14 anthropogenic pressures on primate persistence include the widespread loss and degradation of natural

15 habitats caused by the expansion of industrial agriculture, pastureland for cattle, logging, mining, and

16 fossil fuel extraction. This is the result of growing global market demands for agricultural and non-

17 agricultural commodities. Here we profile the effects of international trade of forest-risk agricultural and

18 non-agricultural commodities, namely soybean, oil palm, natural rubber, beef, forestry products, fossil

19 fuels, metals, minerals, and gemstones on habitat conversion in the Neotropics (Mexico, Central America,

20 and South America), Africa, and South and Southeast Asia. Total estimated forest loss for these regions

21 between 2001 and 2017 was $c a 179$ million ha. The average percent of commodity-driven permanent

22 deforestation for the period 2001-2015 was highest in Southeast Asia (47\%) followed by the Neotropics

23 (26\%), South Asia (26\%) and Africa (7\%). Commodities exports increased significantly between 2000

24 and 2016 in all primate-range regions leading to the widespread conversion of forested land to

25 agricultural fields and an increase in natural resource extraction. In 2016, US \$1.1 trillion of natural- 
26 resource commodities were traded by countries in primate-range regions. The Neotropics accounted for

$2741 \%$ of the total value of these exports, Southeast Asia 27\%, Africa 21\%, and South Asia 11\%. Major

28 commodity exporters in 2016 were Brazil, India, Indonesia, Malaysia and South Africa, countries of high

29 primate diversity and endemism. Among the top 10 importers were China, the US, Japan, and

30 Switzerland. Primate range countries lag far behind importer nations in food security and gross domestic

31 product per capita, suggesting that trade and commodity-driven land-use have done little to generate

32 wealth and well-being in primate habitat countries. Modeling of land-use and projected primate

33 population decline by 2050 and 2100 under a business as usual scenario for 61 primate-range countries

34 indicate that each country is expected to see a significant increase in the number of species threatened

35 with extinction. To mitigate this impending crisis, we advocate the "greening" of trade, a global shift

36 towards a low-meat diet, reduced consumption of oil seed, diminished use of tropical timber, fossil fuels,

37 metals, minerals and gemstones from the tropics, accompanied by a stronger and sustained global resolve

38 to regulate and reverse the negative impacts of unsustainable commodity trade on income inequality, and

39 the destruction of primates and their habitats.

40

41 


\section{INTRODUCTION}

43 International commodities trade has become the backbone of many of the world's economies.

44 Each year, trade in just a handful of agricultural and non-food commodities such as soy, palm

45 oil, and minerals drive billions of dollars of investment in both producer and consumer nations

46 (Henders et al., 2015; Henders et al., 2018; MacDonald et al., 2015). The volume of food and

47 non-food commodities traded globally has increased by over $60 \%$ since the turn of the century,

48 with four trillion US dollars of natural resource commodities traded in 2016 (Chatham House

49 2018; https://resourcetrade.earth/). The trade of these commodities has had a direct impact on

50 land-use change and environmental and social policies in exporting countries (Henders et al.,

512015,2018 ), and in many instances these policies, driven by the over-consumption of a few

52 major importing countries, have resulted in large-scale deforestation, the poisoning of soil,

53 streams, and rivers, and transformed biodiverse landscapes into monocultures (Gardner et al,

54 2018; MacDonald et al., 2015; Moran, et al., 2016). The demand for agricultural products and

55 other commodities in importing countries is increasingly being met by global supply chains

56 associated with multinational corporations rather than local producers (Yu et al., 2013), a process

57 that weakens the ability of exporting countries to sustainably manage their own natural resources

58 (Meyfroidt et al.,2013; Lambin \& Meyfroidt, 2011). Thus, the environmental costs of production

59 have been disproportionately borne by exporting nations, and both exporting and importing

60 countries have become ever more dependent on external and distant resources to satisfy their

61 food and natural resource security needs (Fader et al., 2011, 2013; MacDonald et al., 2015).

62 Global market demands for forest-risk commodities (e.g., soybeans, palm oil, hardwoods and

63 other commodities that contribute significantly to the conversion of biodiverse forests into

64 monocultures or highly degraded habitats) have resulted in a process of rapid and widespread 
65 industry-driven deforestation, negatively impacting tropical biodiversity, subdividing single large

66 or continuous wild animal populations into small and isolated subpopulations, reducing habitat

67 suitability and gene flow, and limiting the area available for species distribution and population

68 persistence (Chaudhary \& Brooks, 2018; Henders et al., 2015, 2018; Wich et al., 2014; Estrada

69 et al., 2017, 2018; Li et al., 2018). Today, commercial agriculture at local and global scales is the

70 most significant driver of deforestation worldwide (Hosonuma et al., 2012).

72 Clearly, trade is a vital component of food security and all countries are dependent on the global

73 food trade. Approximately $25 \%$ of all the food produced for human consumption crosses

74 international frontiers (D’Odorico \& Laio, 2014). Trade helps food security by providing a

75 safety measure against oscillations in domestic food supply and by stabilizing prices (World

76 Bank, 2015). Yet, trade dependence also means that all countries are vulnerable to shifts in the

77 trade policies of food-exporting nations, and to the disruption of supply chains associated with

78 political instability, catastrophic weather events, trade wars, and export bans (Bettina, 2015;

79 Fruch et al., 2019). Because the international trade of commodities is widespread and growing,

80 and land conversion permanently alters natural habitats, effective management plans and

81 conservation initiatives require a comprehensive understanding of the local, regional, and global

82 impacts of consumption on biodiversity and environmental sustainability (Chaudhary \& Brooks,

83 2017; Chaudhary \& Mooers, 2018).

85 A major goal of this manuscript, is to examine the environmental impacts of the international

86 trade of essential agricultural and nonagricultural commodities (e.g. trade flows) on primate

87 habitats and population persistence in the major regions of the world that harbor wild primates 
88 (prosimians, tarsiers, monkeys, and apes): the Neotropics, Africa (for the purposes of this

89 manuscript, we include Madagascar as part of Africa), South Asia, and Southeast Asia.

90 Nonhuman primates are our closest biological relatives, represent the third most specious Order

91 of Mammals, and play an essential role in the maintenance and regeneration of the tropical and

92 temperate ecosystems they inhabit (Estrada et al., 2017). Current information indicates the

93 existence of 512 primate species in 79 genera distributed in 91 countries. Alarmingly, the

94 populations of about $75 \%$ of all primate species are declining and more than $60 \%$ of the species

95 are now threatened with extinction (IUCN Red List., 2019). Major anthropogenic pressures on

96 primate population persistence are land cover changes caused by industrial agriculture, the

97 expansion of pasture for cattle ranching, and increasing logging, mining, and fossil fuel

98 extraction. These activities result in habitat loss and fragmentation, and the disruption of natural

99 ecosystems caused by the building of dams and mega-dams, and the expansion of road and rail

100 networks for resource extraction, along with the colonization of frontier forests, bushmeat

101 hunting, the illegal trade of primates as pets and for their body parts, and the spread of human

102 and domestic animal-borne infectious diseases. These drivers commonly act in synergy,

103 exacerbating primate habitat loss (including in protected areas) and population decline (Estrada

104 et al 2017, 2018). In most primate habitat countries, these pressures arise in the context of an

105 expanding human population with low levels of socioeconomic development, income inequality,

106 political instability, weak governance and the ongoing export trade of agricultural and non-food

107 commodities to international markets (Estrada et al., 2017, 2018; Li, et al., 2018). Therefore, a

108 second goal of our manuscript is to document the Global Food Security Index (FSI) and the

109 Gross Domestic Product per Capita (GDPPC) for exporter and importer countries and discuss 
110 their relationship to consumer nation driven international trade, social well-being, and primate

111 conservation.

Insert Fig. 1 about here

\section{SURVEY METHODOLOGY}

114 We collected and integrated information from several international databases. First, using

115 information from the Global Forest Watch database for the period 2001 to 2017, we profiled

116 forest loss (loss of $>30 \%$ canopy cover) and commodity-driven deforestation (2001 to 2015) for

117 primate-range countries. Commodity driven deforestation refers to permanent conversion and

118 total clearing of forest to nonforest land for the purpose of agricultural (e.g. oil palm, soybeans,

119 natural rubber; Henders et al., 2015; Curtis et al., 2018) or cattle (beef) production. The

120 extraction of other commodities, such as land-based fossil fuels and ores, also results in forest

121 loss and degradation due to the clearing of vegetation, and in the pollution of air, soil, and water.

122 (Alvarez-Berrios \& Aide, 2015; Asner et al., 2013; Global Forest Watch, 2018). Terminology

123 used here for forest loss and commodity-driven deforestation is from Global Forest Watch

124 (2018) and from Curtis et al., 2018. Commodity production was profiled for 20 primate-range

125 countries in the Neotropics, 35 in Africa, six in South Asia and 14 in Southeast Asia (see Fig. 1).

127 Second, using Chatham House's international trade database, resoucetrade.Earth, we

128 documented, for most countries in each primate-range region, the trade exports in 2016 of four

129 agricultural commodities that contribute to forest fragmentation, degradation and habitat loss:

130 soybeans, oil palm, natural rubber, and beef products (Ahrens et al., 2015; Curtis et al., 2018;

131 Henders et al., 2015), and four nonagricultural forestry products: fossil fuels, metals, minerals,

132 and gemstones. We selected these eight commodities because they are among the most

133 commonly traded worldwide. We used information from the year 2016 because it represents the 
134 most complete and up-to-date data set (Beckman et al., 2017; Clapp, 2015; European

135 Commission, 2013; FAO, 2018a,b; MacDonald et al., 2015; resourcetrade.Earth, 2018). For a

136 list of all commodities examined on resourcetrade.Earth see Text S1. Given the negative effects

137 of these commodities on natural ecosystems, we identified the countries that were the major

138 exporters in each primate-range region in 2016, as well as the consumer nations that were the

139 major importers of these commodities. Commodities terminology follows UNComtrade

140 (https://comtrade.un.org) and resourcetrade.Earth (https://resourcetrade.earth/).

142 Third, agricultural and nonagricultural trade is principally an economic exchange, where food or

143 non-food products are provided by exporting nations to importing states in exchange for revenue

144 (Anderson, 2010). This exchange can be examined in monetary value (US\$) or mass traded (e.g.,

145 tonnage). We used monetary value as increases in value are strongly correlated with increases in

146 the volume of commodities sold to importing countries as well as with the revenues generated by

147 exporting countries (MacDonald et al., 2015). Value also can be viewed as a general measure of

148 the footprint of importing countries on land-use practices in primate-range countries. Value

149 similarly allows for a direct assessment of the magnitude of trade flows and can be correlated

150 with other economic indicators such as GDP (MacDonald et al., 2015). With this in mind, we

151 estimated the total revenue generated by the trade of commodities in 2016 by countries in each of

152 the primate-range regions and compared this to the revenue reported for the year 2000.

153

154 We also assessed trends in the expansion of land area used to cultivate soy, oil palm, and natural

155 rubber trees between 1960 and 2016 in the Neotropics, Africa, South Asia, and Southeast Asia,

156 using information from FAOSTATS (Statistical division of the Food and Agriculture 
157 Organization of the UN; http://www.fao.org/faostat/en/\#compare). Similarly, we analyzed

158 growth in the number of cattle produced between 1960 and 2016 in primate-range regions, based

159 on data available in the same database, and compared this to the growth in exports of beef by

160 primate-range nations. Complementary information on commodity trade was obtained from the

161 International Trade Centre (http://www.intracen.org/itc/market-info-tools/trade-statistics/), the

162 UNComtrade database (https://comtrade.un.org) and the FAO trade database

163 (http://www.fao.org/faostat/en/\#compare). Because the international trade in agricultural

164 products influences human food security across primate-range countries and regions, we

165 examined the Global Food Security Index 2018 (FSI) of The Economist Intelligence Unit

166 Limited (https://foodsecurityindex.eiu.com/) for each primate-range commodity exporter

167 country, and for importer nations. The FSI defines food security as the state in which people at

168 all times have physical, social, and economic access to sufficient and nutritious food that meets

169 their dietary needs for a healthy and active life. This framework is based on the internationally

170 accepted definition established at the 1996 World Food Summit (http://www.fao.org/WFS/). The

171 FSI uses three central pillars of food security — affordability, availability, and quality and safety,

172 and ranges from 0 (lowest food security or highest food insecurity) to 100 (highest food security;

173 see Text S3). We obtained, from the World Bank, Gross Domestic Product per Capita (GDPPC)

174 values for 2017 for primate-range exporting countries and for importer countries

175 (https://data.worldbank.org/indicator/NY.GDP.PCAP.CD) and used these as indicators of the

176 economic standing of primate-range commodity exporting countries compared to countries

177 importing these products. Each of the agencies that we used as sources of data specify in their

178 portals the constraints of the data they present. We consider that, although in some cases the 
179 numbers reported may vary in their level of accuracy, the patterns and trends within and between

180 each country or region are reliable with high confidence.

181

182 To illustrate international trade flows of commodities exported by primate-range regions and

183 countries we developed Sankey flow diagrams by using the open access software SankeyMatic

184 accessible in http://sankeymatic.com/build/. In these diagrams we used the accumulated value in

185 SUS as a general indicator of the footprint of importing nations. Important to consider in this

186 assessment is the magnitude of the revenue accrued by each country that exports commodities.

187

188 Modeling the current and future $(2050$ \& 2100) risk of primate extinctions

189 We calculated the number of primate species currently threatened with extinction in each

190 country, and compared this to the expected number of additional primate species in each country

191 that will be threatened with extinction by 2050 and 2100 as a result of land use changes

192 associated with forest-risk trade commodities. We examined six alternative scenarios. We used

193 the approach presented by Chaudhary \& Mooers (2018) that links the countryside species-area

194 relationship (SAR) model (Chaudhary and Brooks, 2017) with the current (2016) and future

195 (2050 and 2100) global gridded maps generated by the six RCP-

196 SSP combination scenarios (RCP 2.6 SSP-1, RCP 4.5 SSP-2, RCP 7.0 SSP-3, RCP 3.4 SSP-4,

197 RCP 6.0 SSP-4, and RCP 8.5 SSP-5), available from the most recent land use harmonization

198 (LUH2) dataset (http://luh.umd.edu/data.shtml: Table S9). We also allocated the total number of

199 primate species threatened with extinction to 10 individual human land use types in the LUH2

200 database, taking into account each species' ability to utilize each of these altered habitats (IUCN, 
201 2015) and to identify the major land use drivers threatening primate species in each country

202 (Chaudhary \& Mooers, 2018). See Text S4 for details on the methodology used.

203

204 We are aware that based on biogeography, differences in climate and topography, and historical

205 patterns of economic development, land conversion, and political control, subregional or local

206 variation in species richness within a country or among neighboring countries exists and

207 therefore the use of a regional approach to primate conservation can mask fine-grained cause and

208 effect relationships between commodity production and primate diversity. For example, in the

209 Neotropics two neighboring countries, Brazil and Argentina differ by a factor of 20 in their

210 number of primate species. Although global commodities trade in each country is having a

211 highly negative effect on ecosystem's health and biodiversity, the number of primate species

212 impacted in Brazil is significantly greater than in Argentina. Similarly, different parts of the

213 same country may vary considerably in both primate diversity and the environmental affects of

214 commodities trade. Bearing this in mind, and given the recent expansion of international

215 commodity trade throughout primate-range countries, we feel that the data we present are best

216 considered indicators of general trends at the global and regional scales.

RESULTS 
223 Data from the Global Forest Watch database on forest cover loss ( $>30 \%$ canopy cover) and

224 commodity-driven deforestation for the period 2001 to 2017 show that both forest loss and

225 commodity-driven deforestation were widespread in countries in the four primate-range regions

226 (Table 1, Fig. 2 A-D). The Neotropics was the region with most forest loss (83.5 million ha)

227 followed by Southeast Asia with 54.3 million ha (Table 1). Africa ranked third with 38.5 million

228 ha, and South Asia fourth with 1.9 million ha (Fig. 2, Table 1). Total estimated forest loss for

229 these regions over this 15 -year period was 178.8 million ha, with an annual rate of forest cover

230 loss of 10.52 million ha/yr (Table 1). The average percent of commodity-driven permanent

231 deforestation for the period 2001-2015 was highest in Southeast Asia (47\%) and lowest in

232 Africa (7\%) (Fig. 2, Table 1).

233

Insert Table 1 about here

234 Globally, the primate-range countries with the highest percentage of commodity-driven

235 deforestation relative to total forest loss for the period 2001-2015 were Malaysia (91\% of 7.3

236 million ha), Paraguay (90\% of 5.5 million ha), Indonesia ( $89 \%$ of 24.4 million ha), Argentina

237 (82\% of 5.2 million ha), Bolivia ( $70 \%$ of 4.5 million ha), and Brazil (66\% of 51 million ha) (Fig.

238 2, Table 1, Fig. S1). Many of these countries have high primate diversity. In the Neotropics,

239 Brazil (the primate-richest country with 116 species) stands out among the top five commodity

240 producing countries in the region due to the disproportionate degree of forest loss during

241 2001-2017 (Fig. 2A). In Africa, the DRC, with 49 primate species, experienced the greatest

242 amount of deforestation, mainly due to shifting agriculture and the extraction of forestry products

243 (Fig. 2B). The DRC was followed by Madagascar, Mozambique, Angola, Ivory Coast, and

244 Tanzania (Fig. 2B). While shifting agriculture was a dominant cause of deforestation in Africa,

245 several countries in this region were heavily involved in the production of export commodities 
246 (e.g., Madagascar, Ivory Coast, Liberia, Nigeria Uganda, Kenya, Equatorial Guinea, and Rwanda

247 among others) (Fig. 2B, Table S1). During the period 2001-2017, Madagascar deforested more

248 land (3.7 million ha) than all mainland African countries except for the DRC. Twenty-seven per

249 cent of forest loss in Madagascar was due to commodity deforestation (Fig. 2B). This is

250 consistent with a recent study based on remote sensing indicating that between 2001 and 2015,

$25127 \%$ of global forest loss ( $>30 \%$ canopy cover) worldwide was attributed to deforestation

252 through permanent land use change for commodity production. The remaining loss was

253 attributed to forestry (26\% was due to natural forests being cut down and trees being planted for

254 wood-based products), shifting agriculture (24\%), and wildfires (23\%) (Curtis et al., 2018). Over

255 the last 3-4 decades, industrial agribusiness and industrial logging have been producing wood

256 products for global rather than local markets (Rudel et al., 2009), with the result that commodity-

257 driven agriculture and logging are, currently, the most significant human-induced drivers of

258 forest loss and forest degradation worldwide (Hosonuma et al., 2012). Notwithstanding corporate

259 pledges, the rate of commodity-driven forest loss has not lessened and, in order to end

260 deforestation, companies will need to eliminate five million hectares of converted forest from

261 supply chains each year (Curtis et al., 2018).

262

Insert Fig. 2 about here

263 INTERNATIONAL COMMODITIES TRADE

264 Growth of commodity exports by countries in primate-range regions

265 Trade data show that, between 2000 and 2016, agricultural and nonagricultural commodity

266 exports increased by a factor of two to four for primate-range countries, suggesting a global trend

267 in the growth of market demands, higher production of commodities, and an expanding land use

268 footprint by importing nations (Fig. 3A). These data also indicate that, in both 2000 and 2016, a 
269 significant share of these imports was purchased by countries in the G-20 group (Fig. 3A). In

270 2016, for example, primate -range regions exported US\$ 1.1 trillion in natural resource

271 commodities. The G-20 group took $60 \%$ of commodity exports by countries in the four primate-

272 range regions. This is consistent with the fact that, in 2016, demand from G-20 countries

273 accounted for over half of all of the world's resource imports (https://resourcetrade.earth/) and

274 emphasizes the disproportionate land use footprint of a few consumer nations. A list of countries 275 in the G-20 group can be found in Table S2.

276

277 In 2016, countries in all primate regions were commodity exporters, but the relative importance 278 of particular commodities varied from region to region. In the Neotropics, the commodity groups 279 most commonly exported were agricultural products, metals and minerals, and fossil fuels (Fig. 280 3B). In Africa, metals and minerals and fossil fuels were the predominant exports. In both South 281 Asia and Southeast Asia the principal exports were fossil fuels and agricultural products.

282 Forestry products were a commonly exported commodity in Southeast Asia (Fig. 3B). Clearly, 283 global market demands for commodities are an important source of income for the economies of 284 primate-range countries. This has come at the cost of the permanent conversion of natural 285 habitats into anthropogenic landscapes, causing the loss of biodiversity and significant declines 286 in primate populations (Fig. 2) (Chaudhary and Brooks, 2017; Chaudhary \& Mooers, 2018; 287 Estrada et al., 2018).

Insert Fig. 3 about here

289 Trade in commodities leading to permanent deforestation Regional patterns

291 Below, we profile the international trade of soybeans (Glysine max), palm oil (Elaeis guineensis), 292 and natural rubber (Hevea brasiliensis) that results in permanent deforestation. We also examine 
293 beef production, a major driver of the conversion of forests to pasture. Data, from

294 resourcetrade.Earth, on the international trade in these four commodities, indicates exponential

295 growth (US bn) between 2000 and 2016, and this has differentially affected permanent

296 deforestation across primate range regions (Fig. 4). For example, in both 2000 and 2016,

297 soybeans dominated exports in the Neotropics. This region was also the principal exporter of

298 beef during that period (Fig. 4). Southeast Asia was the leading exporter of palm oil and rubber

299 in both 2000 and 2016. The other primate range regions contributed smaller volumes to the trade

300 in these commodities (Fig. 4).

301

Insert Fig. 4 about here

302 Expansion of land area for production of agricultural commodities between 1960 and 2016

303 Data from FAOSTATS show that the production of soybeans in the Neotropics and Southeast

304 Asia has steadily increased since 1960. In 2016, soybeans production involved almost 74 million

305 ha of land in primate range countries, of which some $80 \%$ was in the Neotropics, particularly

306 Brazil and Argentina (Fig. 5A). In 2016, some 15 million ha of land in Southeast Asia were

307 devoted to palm oil production (about 20 million ha worldwide). The conversion of forested land

308 for the production of palm oil in Southeast Asia has increased steadily since 1970 (Fig. 5B).

309 Overall, soybeans and oil palm have become increasingly important not only as food products

310 for humans and domestic animals, but also for biofuel production (Koh \& Ghazoul, 2008). In

311 1960, 4 million ha worldwide were devoted to the cultivation of natural rubber. By 2016, this

312 had increased to 11.4 million ha, with Southeast Asia accounting for about $78 \%$ of the total (Fig.

313 5C).

314

Insert Fig. 5 about here

315 Trade flows in $\mathbf{2 0 1 6}$ of agricultural commodities resulting in permanent forest loss

316 Soybeans

PeerJ reviewing PDF | (2019:03:35624:1:2:NEW 24 Apr 2019) 
317 In 2016, a total of US $\$ 48.72$ bn in soybeans was exported by primate-range countries (this

318 involved almost 74 million ha of land), of which 92\% were exports by Brazil and Argentina, two

319 countries in the Neotropics (Fig. 6A). Brazil, with 116 primate species, was the second largest

320 producer of soybeans in the world (the US was the top producer, USDA, 2018), and contributed

321 approximately $80 \%$ of the soybeans crop exported by primate-range countries

322 (https://globalforestatlas.yale.edu/amazon/land-use/soy). In Brazil, 30\% of deforestation between

3232000 and 2010 was driven by global demand for soybeans and beef exports (Karstensen et al.,

324 2013). While direct deforestation for soybeans production in the Amazon has remained low, it

325 has become progressively common in the Cerrado region of Brazil (Beckman et al., 2017; Gibbs

326 et al., 2015; Zalles et al., 2019), where 28 primate species are found (IUCN Red List 2019-1,

327 2019). Other primate-habitat countries that are significant exporters of soybeans are Argentina,

328 Bolivia, and Paraguay. Most deforestation in Bolivia has been in the Amazon basin where

329 expansion of soybeans agriculture has intensified and where 24 primate species occur (Muller et

330 al., 2012; Zales et al., 2019). Other countries in Africa, South Asia, and Southeast Asia

331 contributed lesser amounts to the international trade in soybeans (Fig. 6A). China led the import

332 market in 2016 (Fig. 6B), followed by India, the Netherlands, and Vietnam. Much smaller

333 amounts of soybeans were purchased by countries in South Asia, Southeast Asia, and Africa

334 (Fig.

335 6B). In Brazil ca 70\% of soybeans exports in 2016 was turn into soymeal used as livestock feed

336 (Delgado, 2005; Fuchs et al., 2019; Mielke \& Mielke, 2018) and soy oil (a derivative of soymeal

337 production) is used by the food industry to produce soy sauce, cooking oil, miso, soy milk, soy

338 curd, tempeh, and tofu products. It is also used in the production of detergents, cosmetics, and

339 various industrial chemicals (Casson, 2003; USDA-FAS, 2018). 
341 Oil palm

342 The total accumulated value of exports of palm oil by primate-range nations in 2016 was

343 US\$15.42 bn, with 95\% of the production from Indonesia and Malaysia (Fig. 6C). Clear-cutting

344 for wood and to establish oil palm plantations are common patterns in these two countries

345 (Henders et al., 2015). With 56 species, Indonesia is the primate richest country in Southeast

346 Asia. Malaysia has 20 primate species (Estrada et al., 2018). Oil palm imports from Southeast

347 Asia were purchased, in 2016, principally by India, China, the US, Italy, and Germany (Fig. 6D).

348 Primate-range countries in the other regions contributed smaller amounts to the palm oil trade.

349 Data from FAOSTATS show that cultivation of oil palm has expanded greatly in Southeast Asia

350 from 5.5 million ha in 2000 to 15 million ha in 2016 (Fig. 5B). Growing global demand for oil

351 palm products is a major cause of rapid decline in the remaining populations of the Critically

352 Endangered Sumatran and Bornean orangutans (Pongo abelii and Pongo pygmaeus,

353 respectively) and a serious risk for the Endangered or Critically Endangered chimpanzees,

354 bonobos, and gorillas in Africa, because a large proportion of extant populations are found

355 outside protected areas (Grasp \& IUCN, 2018; Lanjouw et al., 2015; Linder, 2013; Vijay et al.,

356 2016; Wich et al., 2014). Projections of land-cover change indicate that the Bornean orangutan,

357 for example, is expected to lose 15 to $30 \%$ of its remaining habitat by 2080 , mainly due to

358 deforestation and oil palm plantations (Nantha \& Tisdell, 2009; Struebig et al., 2015; Vijay et al,

359 2016; Wich et al., 2014). Moreover, given the growing global demand for palm oil, which is

360 expected to convert some 400 million ha of African forest to monoculture by the year 2050,

361 population decline and habitat loss is projected to threaten over 40 species of African primates

362 (Strona et al., 2018). The oil palm, native to West Africa, is now cultivated in large-scale 
363 plantations across the tropics. It is used in several commercial products including cooking oil,

364 soap, cosmetics, and margarine (USDA-FAS, 2018).

365

366 Natural rubber

367 The total accumulated value of exports of natural rubber by top exporter primate-range countries

368 in 2016 was US $\$ 11.1$ bn and the most important primate-range region for supplying natural

369 rubber to global markets was Southeast Asia, with Thailand and Indonesia contributing to $76 \%$

370 of the total value of exports (Fig. 7A). Major importing countries were India, China, and the US

371 (Fig. 7F). Exports of rubber from Southeast Asia went from 4.3 US\$ bn in 2000 to almost 11

372 US\$ bn in 2016, a reflection of the dramatic expansion of rubber plantations over the past several

373 decades (Fig. 5C). In 1960, four million ha worldwide were devoted to rubber cultivation and,

374 by 2016 , the area of land converted to rubber plantations had reached 11.4 billion ha, with

375 Southeast Asia accounting for approximately 78\% (Fig. 5C; Fig. 8). Deforestation due to the

376 establishment of rubber plantations in South Asia and China has severely affected populations of

377 threatened primates such as the Vulnerable Bengal slow loris (Nycticebus bengalensis), the

378 Endangered western hoolock gibbon (Hoolock hoolock), the Endangered Phayre's langur

379 (Trachypithecus phayrei), the Critically Endangered northern white-cheeked crested gibbon

380 (Nomascus leucogenys), and the Critically Endangered Hainan gibbon (Nomascus hainanus)

381 (<30 individuals left; Fan et al., 2014; Mazumder, 2014). Even protected areas are at risk due to

382 the expansion of rubber plantations. Between 2005 and 2010 , over $2500 \mathrm{~km}^{2}$ of natural tree

383 cover and $610 \mathrm{~km}^{2}$ of protected areas were converted to rubber plantations across Southeast Asia

384 (Ahrens et al., 2015). Growing global market demands for natural rubber are driving both

385 industrial-scale and smallholder monocultures of this commodity, with $>2$ million ha established 
386 in the last two decades, mostly in Southeast Asia and southwest China, including the primate-

387 rich province of Yunnan (Li et al. 2018). It is estimated that an additional eight million ha of

388 rubber plantations will be required to meet world demand by 2024 (Warren-Thomas et al.,

389 2015). Global demand for natural rubber also has increased rapidly in the past decades, with $70 \%$

390 of global consumption used for tires. Rubber is the most rapidly expanding tree crop in mainland

391 Southeast Asia (Ahrens et al., 2015; Warren-Thomas et al., 2015).

392

Insert Fig.7 about here

393 Beef

394 The total accumulated value of exports of beef by top exporter primate range nations in 2016 was

395 US $\$ 13.2$ bn. The most important primate-range region supplying beef to global markets in 2016

396 was the Neotropics. In both the Neotropics and South Asia, beef exports increased significantly

397 between 2000 and 2016 (Fig. 4D). Trade flows show that beef exports in the Neotropics were

398 dominated by Brazil, Mexico, Argentina, and Paraguay, accounting for $63 \%$ of beef exports from

399 this region (Fig. 7C). In 2016, China, the Russian Federation, and Egypt were the top importers

400 of beef from the Neotropics, suggesting that these countries drive the destruction and conversion

401 of large areas of forested land in this region (Fig. 7D). In South Asia, India was the major beef

402 exporter, accounting for 95\% of exports (Fig 7C). Imports of South Asian beef went principally

403 to Egypt, Malaysia, Saudi Arabia, and the UAE (Fig. 7D). As a result of internal and global

404 demands for beef, cattle stocks have been growing rapidly since 1980 in both the Neotropics and

405 Africa, and at a slower rate in South Asia and Southeast Asia. However, collectively in these

406 four primate regions, cattle stocks have grown from 527.7 million head in 1960 to 1 billion head

407 in 2016 (Fig. 5D), with concomitant increases in pasture land and extensive use of rangelands

408 placing many primate populations at risk (Estrada et al., 2017). 


\section{Trade in nonagricultural commodities leading to forest degradation}

411 The international trade in forestry products (e.g., lumber and charcoal), land-based fossil fuels,

412 metals and minerals, and gemstones from primate-range regions is a major driver of forest

413 degradation and loss (UNComtrade, 2018). Trade data indicate that the export of these

414 commodities grew substantially between 2000 and 2016 (Fig. 9A-D)). The Neotropics and

415 Southeast Asia were major exporters of forestry products, while Southeast Asia and the

416 Neotropics dominated exports of fossil fuels. Major exporting regions of metals and minerals

417 were the Neotropics and Africa, while major exporters of gemstones and pearls were South Asia 418 and Africa (Fig. 9A-D).

Insert Fig. 9 about here

\section{Trade flows in 2016 of nonagricultural commodities resulting in forest degradation}

Forestry products

422 The total accumulated value of exported forestry products by the top exporting primate-range nations in 2016 was US\$21 bn. Trade flow data show that while all four of the primate-range regions exported forestry products, the Neotropics and Southeast Asia were the greatest exporters (Fig. 10A). In the Neotropics, the top exporter of forestry products in 2016 was Brazil, and the top importer nations were China and the US, followed by Italy, Germany, and Japan 427 (Fig. 10B). Top exporters of forestry products in Southeast Asia were Indonesia and Malaysia, 428 followed by Thailand and Vietnam (Fig. 10A). China, Japan, and South Korea were the top 429 importers of forestry products from Southeast Asia (Fig. 10B). Major importers of forestry 430 products from Africa were China, India, Belgium, and France (Fig. 10B). In addition, the total 431 accumulated export of wood from the Congo Basin countries - which have some 60 primate 432 species - to China doubled between 2001 and 2015, with a concomitant increase in the loss of 
433 tree cover (Fuller et al., 2018). Global demand for tropical forestry products (e.g., timber) has

434 increased over the past several decades. This has led to an expansion of logging activities

435 creating a potent economic incentive for road building in otherwise forested and hard to access

436 areas in primate-range regions (Malhi et al., 2014). Data from FAOSTAS show that harvesting

437 industrial non-coniferous roundwood increased by an order of magnitude between 1960 and

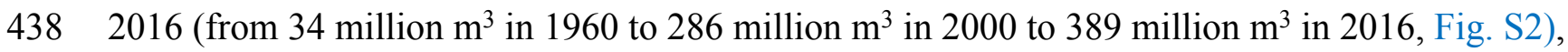

439 in response to the ever-increasing worldwide demand for tropical timber. Complex

440 environmental and economic drivers surround the trade of tropical timber and deforestation. For

441 example, US demand for Chinese-made furniture positively correlated with Chinese timber

442 imports from the Congo Basin, suggesting that the US demand for furniture motivates the

443 harvest of timber by Chinese commercial businesses (Fuller et al., 2018). Although some

444 primate species — orangutans (Pongo), for example — can survive temporarily in logged forests,

445 they and other primate species such as chimpanzees (Pan troglodytes troglodytes) and gorillas

446 (Gorilla gorilla gorilla) are adversely affected, and their long-term persistence in these degraded

447 habitats is unlikely (Meijaard et al., 2012; Voigt et al., 2018; Morgan et al., 2018). Logging

448 reduces canopy cover and forest undergrowth, and consequently humidity. The drying of the

449 subcanopy and undergrowth increases tree mortality and the likelihood of ground fires, affecting

450 the regeneration of the large tree species that provide food, resting sites, and refuge for primates

451 (Alisjahbana \& Busch, 2017; Lewis et al., 2015; Peres, 1999, 2001; World Bank, 2016).

452 Moreover, the influx of hunters, miners, and settlers has led to the pollution of streams and an

453 increase in bushmeat hunting (Remis et al., 2012).

454

455 Fossil fuels (coal, gas, oil) 
456 The total accumulated value of exports of fossil fuels by the top exporting primate-range nations

457 in 2016 was US\$258 bn (Fig. 10). Fossil fuel exports increased markedly in the Neotropics, 458 mainland Africa, and Southeast Asia between 2000 and 2016 (Fig. 9A-C). In the Neotropics,

459 Venezuela, Colombia, and Mexico (Fig.10C) were the leading exporting nations. The leading

460 importer nations were the US, China, and India (Fig. 10D). In mainland Africa, exports of fossil

461 fuels in 2016 were greatest in Nigeria and Angola, and major importers were China, India, and

462 the US (Fig. 10C). In Southeast Asia, Indonesia and Malaysia were the main exporters of fossil

463 fuels, with China, Japan, Singapore, and South Korea being the major importers (Fig. 10D). In

464 South Asia, India was the largest producer of fossil fuels and the major importers were Singapore

465 and the US (Fig. 10C, D). Global demand for oil and natural gas is expected to grow between

$46630 \%$ to $53 \%$ by 2035, and primate-rich areas such as the Amazon, Malaysia, and Borneo will be

467 severely affected (Finer et al., 2015). Oil and gas concessions in the western Brazilian Amazon

468 and in forested areas of Colombia, Ecuador, Perú, and Bolivia, already cover about 733,414 km²

469 (Finer et al., 2015). At the time of writing, 327 oil or gas blocks, covering some 108 million ha,

470 are projected or are being explored in the Amazon Basin (Bebbington et al., 2018). In many

471 cases, these potential energy fields have considerable overlap with protected areas, and currently

472 exploited oil and gas infrastructure tends to be found on land where biodiversity, species

473 richness, and range rarity are high (Hartfoot et al., 2018). This exacerbates the negative effects

474 that fossil fuel extraction have on primate populations. Human societies are largely dependent on

475 fossil fuels (coal, oil, and natural gas), which has contributed to increased carbon in the

476 atmosphere and to climate change. The land-based extraction of fossil fuels, similar to the

477 negative impact of the harvesting of forest products, results in decreased biodiversity and 
478 increased accessibility for settlements, logging, hunting, and agriculture, all resulting in primate

479 habitat loss and pollution (Hartfoot et al., 2018; Finer \& Orta-Martinez, 2010).

480

Insert Figure 10 about here

481 Metals and minerals

482 The total accumulated value of exports of metals and minerals by the top exporting primate483 range nations in 2016 was US\$204 bn (Fig. 11A-D). The Neotropics was the leading primate 484 region exporting metals and minerals (US\$85.6 bn), followed by Africa (US\$54.5 bn), Southeast 485 Asia (US\$35.0 bn), and South Asia (US\$19.8 bn) (Fig. 11A). Of the countries in the Neotropics, 486 Brazil, Peru, and Mexico were the major exporters of metals and minerals. In Africa, South 487 Africa dominated metal and mineral exports (Fig. 11A). Major exporters in Southeast Asia were 488 Indonesia, Thailand, and Malaysia (Fig. 11A). Pakistan, India, and Afghanistan were major exporters in South Asia (Fig.11A). In 2016, China was the primary importer of metals and minerals from the Neotropics, Africa, Southeast Asia and South Asia. Other leading importers were the US, Switzerland, Japan, South Korea, and India (Fig. 11B). The mining of metals and minerals is a persistent threat to primates and their habitats. Mining contributes to habitat destruction, fragmentation, deforestation, and the poisoning and pollution of soil and ground water (Alvarez-Berrios \& Aide, 2015; Garcia et al., 2017). In Brazil, 126 mining dams are currently at risk of failing. In one case, dam failure poisoned hundreds of kilometers of the Rio Doce, from the upper reaches to the sea, with a toxic mud of iron-ore tailings (Garcia et al., 2017). Added effects are extensive tree mortality on the borders of both small and large mines, 498 the establishment of camps and frontier towns, the construction of access roads, rail, and trails, 499 the construction of mining dams, and hydro-power/waterway developments (Alvarez-Berrios \& 500 Aide, 2015; Asner et al., 2013; Global Forest Watch, 2018). Mining stimulates human migration, 
501 resulting in illegal logging and the colonization of forested areas, with the consequent increase in

502 bushmeat hunting and illegal primate trade (Alamgir et al., 2017; Butt et al., 2013; Laurance et 503 al., 2015).

504

505 In eastern DRC, unprotected areas of high animal and plant biodiversity overlap with areas that 506 are rich in minerals (Edwards et al., 2014). Increased global demand for surface deposits of 507 conflict minerals such as tantalum, coltan, and gold has resulted in the expansion of illegal

508 mining camps in several national parks in the DRC. Widespread bushmeat hunting in these areas

509 has devastated populations of Grauer's gorillas, eastern chimpanzees, and other primate species

510 (Plumptre et al., 2015; Spira et al., 2017). Illegal gold mining in Madagascar by itinerant miners

511 has impacted many forests inhabited by lemurs (Duffy, 2007). In the Philippines, mining of gold,

512 nickel, and copper on Dingaan Island has endangered the survival of tarsiers (Carlito syrichta)

513 (Brown et al., 2014). In Ghana, mining-induced hunting and logging have caused the decline of

514 primates such as the Dwarf galago (Galagoides demidoff), Bosman's potto (Perodicticus potto),

515 and the Mona monkey (Cercopithecus mona) in forest reserves adjoining mine sites (Erasmus et

516 al., 2018). Gold mining in Indonesia is a major threat to the Endangered proboscis monkey

517 (Nasalis larvatus) (Meijaard and Nijman, 2000) and to Bornean orangutans and the Endangered

518 Bornean gibbons (Hylobates muelleri) (Garcia et al., 2017; Lanjouw, 2014). Pressure to expand

519 mining as a result of global market demands has resulted in mining concessions covering 160

520 million ha, some 21\%, of the total area of the Amazon basin (Bebbington et al., 2018). If these

521 concessions are mined, they will have a devastating impact on primate populations and

522 biodiversity.

Insert Fig. 11 about here 


\section{Gemstones and pearls}

525 The total accumulated value of exports of gemstones and pearls by the top exporting primate-

526 range nations in 2016 was US\$45 bn (Fig. 11C). India, Botswana, Thailand, Angola, and

527 Namibia were top exporters of gemstones (Fig. 11C). China, the US, Belgium, and the UAE

528 were major importers (Fig. 11D). Mining for gemstones such as diamonds, emeralds, and

529 sapphires is accompanied by forest degradation, influxes of people, frontier settlements, road

530 building, bushmeat hunting, and the disturbance of protected areas similar to that caused by the

531 mining of metals and minerals (Duffy, 2007). Illegal gem mining coupled with logging in

532 national parks poses a threat to the Endangered fork-marked dwarf lemur (Phaner pallescens) in

533 Madagascar, and to the needle-clawed galagos (Euoticus elegantulus) in Cameroon (Nomuh,

534 2018). Illicit sapphire mining by itinerant miners in Madagascar has had a negative impact on the

535 survivorship of lemurs (e.g., the Endangered ring-tailed lemur, Lemur catta), even in protected

536 areas (Duffy, 2007; Gould \& Sauther, 2016). Many primate range countries are among the most

537 important world producers of diamonds (e.g., Guyana, Brazil, Sierra Leone, Botswana,

538 Tanzania), emeralds (e.g., Brazil, Zambia, Pakistan), sapphires (e.g., Pakistan, Sri Lanka,

539 Madagascar), rubies (e.g., Pakistan, Myanmar, Thailand), jade (e.g., Myanmar), and other

540 colored gemstones (Shortell \& Irwin, 2017). Only a small fraction of the cutting, polishing, and

541 processing of gemstones are conducted in the countries where this resource is extracted (Shortell

$542 \&$ Irwin, 2017). The world production and trading of gemstones is dominated by a small set of

543 international corporations including Rockwell Diamonds, Gem Diamonds, Lucara, Rio Tinto,

544 Petra Diamonds, and De Beers (https://www.petragems.com/education/top-ten-diamond-

545 companies-in-the-world-/), and monies generated by the gem trade are rarely used to support

546 economic development in primate-range countries (Howard, 2016). 
548 Top primate-range, commodity-exporter countries and top importer countries of these 549 commodities

550 Our examination of the 2016 trade flows of the eight major commodity groups indicates that 55

551 primate habitat countries were exporters, and 42 countries were importers (Figs. 10, 11; Table

552 S3, S4). Among the top 10 exporting countries, Brazil, India, Indonesia, Malaysia, and South

553 Africa accounted for $50 \%$ of the accumulated value of commodity exports in 2016 (Fig. 12A:

554 Table S3). Just 10 importer countries accounted for $95 \%$ of the imported value (US\$455 bn) of

555 commodities from those 55 primate-habitat countries (Fig. 12B; Table S4). Among the major

556 importers in 2016, China and the US combined, accounted for $58 \%$ of the imported value of

557 these commodities. However, China was by far the single major importing nation, purchasing

558 over twice the amount of commodities purchased by the US (Fig, 12B). In this regard, along with

559 the US, China's emergence as an economic superpower has resulted in a devastating

560 environmental footprint that is driving deforestation and biodiversity loss in primate-habitat

561 countries (Ascensão et al., 2018).

562

Insert Fig. 12 about here

563 Revenues generated by commodity-exporting, primate-range countries in 2016

564 In 2016, US\$4.4 trillion of natural resource commodities were traded by the world's countries

565 (resourcetrade.Earth, 2018) and 25\% (US\$ 1.1 trillion) were commodities traded by countries in

566 primate-range regions. The Neotropics accounted for $41 \%$ of the total value of these exports,

567 Southeast Asia for 27\%, Africa for 21\%, and South Asia for 11\% (Fig. 13A). Trade data from

568 resourcetrade.Earth indicate that these export revenues increased significantly between 2000 and

5692016 (Fig. 13A). International trade is a critical source of revenue for primate-range countries

570 and, assuming that an increase in the Gross Domestic Product per Capita (GDPPC) has a positive 
571 effect on food security, political stability, education, and health, we expect that it would favor

572 primate conservation. For example, primate-range countries with a GDPPC of $<10,000$ US\$ in

5732018 had a higher percent of IUCN threatened-primate species than countries with a GDPPC of $574>10.000$ US\$ (Fig. 13B. Table S5).

575

576

577

578

579

580

581

582

583

584

585

586

587

588

589

590

591

592

593

594

Insert Fig. 13 about here

Modeling the current and future (2050 and 2100) risk of primate species' extinction due to agriculture

As of 2016, the greatest number of primate species threatened with extinction (i.e. Vulnerable, Endangered, or Critically Endangered according to the IUCN Red List) are in Madagascar, Brazil, Indonesia, China, Vietnam, and Colombia (Table 2). In Madagascar and Southeast Asian countries such as Vietnam, Laos, and China, over $80 \%$ of the primates are threatened with extinction. Primate-habitat countries differ widely in the degree to which particular anthropogenic drivers have resulted in species decline (Table 2). In Table S9, we aggregated 10 human land use patterns of the LUH2 dataset into three broad categories: forestry (defined as any human use of forested land), grazing (defined as pasture or rangeland for commodity production), and agriculture (defined as any crop production), for the top 15 primate-richest countries in the world. At the time of writing, forestry is the major threat to primate species in Peru, Cameroon, Indonesia, Laos, Malaysia, India, and Myanmar. In contrast, the conversion of forest into pasture for grazing, principally for cattle and pig production, is the major threat to primate species in Madagascar, Brazil, Colombia, and China. Among all land use patterns, agricultural activities are the greatest or second greatest threat to primate species in Indonesia, Brazil, Vietnam, Laos, Malaysia, India, Nigeria, Myanmar, Thailand, Cameroon, and Cambodia (see Table S9 for all results per land use type).

Insert Table 2 about here

Peer) reviewing PDF | (2019:03:35624:1:2:NEW 24 Apr 2019) 
595 The business-as-usual future scenario RCP 4.5 SSP-2 (Fricko et al. 2017) assumes continued

596 economic development along historical patterns such that meat and food consumption converge

597 slowly towards higher levels, trade is largely regionalized, and crop yields in low-income regions

598 catch up with high-income nations. In the model, land use changes, however, are incompletely

599 regulated, with continued deforestation (although at a declining rate) between 2016 and 2050.

600 The model predicts that by the year 2050, each primate-habitat country is expected to see an

601 increase in its number of threatened species (Table S8). This includes 13 newly threatened

602 species in Madagascar (100\% of species threatened) and 12 newly threatened primate species in

603 Brazil (44\% of species threatened) (Fig. 14). Land use changes by the end of the century are

604 expected to result in six of the 15 primate-richest countries having $100 \%$ of their primate species

605 threatened with extinction by the year 2100 , and three additional countries having over $80 \%$ of

606 their primate species threatened with extinction (Fig. 14, Table S8). On a more positive note, we

607 found that the most ecofriendly climate change mitigation scenario, coupled with a sustainable

608 socioeconomic trajectory RCP2.6 SSP-1 (Van Vuuren et al. 2017) which is defined as the world

609 shifting towards a sustainable path characterized by healthy diets, low waste, reduced meat

610 consumption, increasing crop yields, and reduced tropical deforestation, is expected to limit land

611 use changes such that over the next 30 years (e.g. by 2050), no additional primate taxa will

612 become threatened with extinction (Table S8). The scenario will require significant changes in

613 human behavior and land use practices.

614

Insert Fig. 14 about here

\section{TRADE AND FOOD SECURITY}

616 Trade is a critical factor in food security and provides an income for approximately $30 \%$ of the

617 world's active workforce (Clapp, 2015). While some countries lack the natural capital to produce

618 enough food because they are restricted by land, climate, soil, political instability, or technology, 
619 other countries produce more food than they require. Open trade policies allow the free flow of

620 food from countries with excesses to countries with deficits and, therefore, are expected to

621 enhance world food security (Lamy, 2011, 2012; OECD, 2013; World Bank, 2012). The

622 Economist Intelligence Unit's 2018 Food Security Index (FSI) ranges from 0 (lowest food

623 security) to 100 (highest food security) (Text S2). In 2018, the mean value of the FSI, available

624 for 43 of the 55 primate-range country commodity exporters was 49.0 (range 27.0 [Madagascar]

625 to 69.2 [Argentina]) (Fig. 13A; Table S6). For the top 10 exporters, the mean FSI was 57.0

626 (range 38.0 [Nigeria] to 68.0 [Brazil]). In contrast, the mean value of the FSI for the top 10

627 commodity importer countries was 76.0 (range 50 [India] to 86 [Singapore]) (Fig. 15A; Table

628 S7). Clearly, primate-range countries that are exporters of commodities lag behind importer

629 nations in food security. These major importing nations tend to capture large volumes of export

630 commodities from primate-range countries with limited positive effects for the exporting

631 countries. This difference is underlined by the disparity in the 2017 GDPPC between these two

632 groups of countries (Fig. 15B).

633

Insert Fig. 15 about here

634 It is expected that trade helps food security by providing a safety net against oscillations in

635 domestic food supply and by stabilizing prices (World Bank, 2015). Trade dependence, however,

636 also means that countries are vulnerable to shifts in the trade policies of both food-importing and

637 food-exporting nations, including tariffs and trade bans (Bloomberg, 2017; Cottrell et al., 2019).

638 Importantly, the interconnectedness of global trade and supply chains creates a risk that the

639 storage and transport infrastructure that governs international trade might collapse (Bettina,

640 2015) — such as when political and physical bottlenecks restrain the flow of food, water, and

641 energy (Bloomberg, 2017). Political conflict is one of the main drivers of food insecurity, 
642 disrupting not only food production and distribution but also transport (World Bank, 2015).

643 Shifts in market prices also have important consequences for consumers. For example, as China

644 pays more for soybeans, whether in response to tariffs on US imports or to broaden its import

645 profile, other consumers will pay more as well (Reuters, 2017). For low-income households

646 around the globe that already spend most of their income on food, abrupt cost increases produced

647 by higher import duties, or by unexpected shifts in trade flows, can have a significant negative

648 impact on health, food security, the spread of disease, and political stability (Bettina, 2015).

649

650 CORRUPTION AND ILLEGAL FOREST CLEARING FOR COMMERCIAL

651 AGRICULTURE

652 Factors that negatively impact human communities, also negatively impact policies and practices

653 of environmental sustainability, and often result in habitat degradation and loss of biodiversity.

654 One such factor is corruption. Information from the 2018 Corruption Perceptions Index (CPI) of

655 Transparency International (https://www.transparency.org) in which $0=$ most corrupt and $100=$

656 least corrupt, showed that commodity exporters in primate-range countries were, on average,

657 more corrupt (average CPI of 33.1; range:18.0 - 68.0; Table S6) than importer countries

658 (average CPI of 52.8; range 20.0 - 85.0; Table S7). Income inequality is often directly associated

659 with corruption. For example, between 2001 and 2015 the richest $10 \%$ of Brazilians accounted

660 for $61 \%$ of total economic growth (Oxfam, 2019a). Similarly, wealth inequality in Indonesia is

661 so extreme that the four richest men in the country have more wealth than the combined total of

662 the poorest 100 million people (Oxfam 2019b). Both Indonesia and Brazil are ranked as the first

663 and third primate-richest countries in the world, and increased corruption and income inequality

664 is projected to result in high levels of environmental degradation, deforestation, and increased 
665 rates of primate extinctions (Estrada et al., 2018).

666

667 A recent report by Forest Trends indicates that since the start of the 21 st century, illegal forest

668 clearing for commercial agriculture and related exports has continued at an alarming rate in

669 tropical regions (https://www.forest-trends.org/). This has resulted in high conservation costs. It

670 is projected that unless governments ensure that forested land converted for production is

671 acquired legally and sustainably, deforestation will continue to increase in regions where little

672 commercial agriculture had previously existed, such as the Congo Basin (Lawsom et al., 2014).

673 Governments that curb political freedom, free speech, a free press, and citizen rights and choices

674 inevitably also have free license to engage in large-scale environmental destruction. The most

675 recent (2019) evaluation by Freedom House, an independent watchdog group, shows that in

676 many countries in Africa, South Asia, Southeast Asia and the Neotropics, individual freedoms

677 have declined precipitously in the last 13 years (Freedom House, 2019), and this is likely to

678 result in a further decline in laws governing environmental and primate protection (Fig. 16).

679

Insert Fig. 16 about here

680 CONCLUSION AND CLOSING COMMENTS

681 The production of commodities such as soybeans, palm oil, natural rubber, and beef has direct

682 and indirect impacts on biodiversity and primate population persistence because plantations are

683 primarily large-scale, commercial monocultures that require complete clearing of natural

684 vegetation. In addition, the use of pesticides and herbicides serve to eliminate remaining native

685 biodiversity, and diminish the likelihood of habitat restoration (Fearnside, 2001; Laurance,

686 2007; WWF, 2010). The extraction of hardwoods, minerals, land-based fossil fuels, and

687 gemstones in undisturbed areas causes extensive forest degradation and forest loss. It also results 
688 in the construction of transportation networks and other infrastructure projects that open large 689 and once remote forests to population migration, illegal logging, bushmeat hunting, and the 690 illegal pet trade, critically impacting primate and other animal populations (Alamgir et al., 2019;

691 Latrubesse et al., 2017; Plumptre et al., 2015; Spira et al., 2017; Timpe \& Kaplan, 2017;

692 Winemiller et al., 2016; WWF, 2006). Unfortunately, a projected massive expansion of

693 transportation networks has been proposed as part of China's Belt and Roads Initiative. This will 694 involve some 60 counties in Africa and Asia through a large-scale expansion of roads and rails in 695 order to create a set of economic corridors designed to expand future global trade. This will 696 result in permanent environmental damage, impacting primates and biodiversity by increasing 697 agricultural production, the extraction of raw materials, as well as the construction of dams and 698 other large infrastructure projects, causing habitat reduction and fragmentation, increasing 699 human-primate conflict (Ascensão et al., 2018; Liu et al., 2019; MERICS, 2019) and contributing 700 to climate change (Barret et al., 2013).

701

702 Furthermore, global dietary changes towards greater meat consumption and greater dependence 703 on vegetable oils as a result of improved living standards will encourage many primate-range 704 countries to convert additional forested land into monocultures to meet national and global 705 market demands (Gouel \& Houssein, 2017; Kastner et al., 2012; Tilman \& Clark, 2014). In order 706 to achieve the goals of primate habitat conservation, it is imperative to decrease the world's 707 demand for agricultural products (e.g. oil seeds, natural rubber, sugar cane) and the consumption 708 of meat and dairy products (Machovina et al., 2015; Ranganathan et al., 2016; Stehfest et al., 709 2009; Willet et al., 2019). It is estimated that the world will need to convert an additional seven 710 million ha of forested land in the tropics to oil palm in the next few years to meet projected 
711 demand increases (Lawsom et al., 2014). Per capita meat-consumption is growing globally and it

712 is anticipated to increase in the approaching decades with an expanding human population, rising

713 incomes in most regions of the world (Henchion et al., 2014), and the rapid emergence of

714 a global middle class (1.8 - 4.9 billion by 2030; Kharas, 2017). Trade evidence suggests that

715 land conversion for the production of forest-risk commodities has expanded rapidly in primate-

716 range regions, placing primate populations at greater risk (Fig. 6; Chaudhary and Brooks,

717 2017). For example, a study that modeled agricultural expansion and primate distributions for the

718 end of the $21^{\text {st }}$ century found that $68 \%$ of the area currently occupied by primates will be turned

719 over to agricultural use, affecting $75 \%$ of primate species worldwide (Estrada et al., 2017). A

720 country level analysis under a 'worst-case' scenario (e.g. expected increase in conversion of

721 forested land to agricultural production) indicated that by the year 2100, the spatial distribution

722 of primates in Brazil will be reduced by $78 \%, 72 \%$ in Indonesia, $62 \%$ in Madagascar, and $32 \%$ in

723 the DRC (Estrada et al., 2018). Combined, these four countries account for approximately $64 \%$

724 of all primate species. In a second study using the same modeling approach, the most 'optimistic'

725 scenario (e.g. strong and effective legislation to protect primates and their habitats) predicted a

$72651 \%$ reduction in the geographical range of primates in China by the year 2100 (China has 25

727 primate species, 9 of which are endemic) and an $87 \%$ reduction under a 'worse case' scenario ( $\mathrm{Li}$

728 et al., 2018). Such extensive land conversion will not only increase the susceptibility of primate

729 species at risk of extinction, but it will exacerbate the effects of climate change and cause severe

730 disruption to local human communities through extreme weather events such as increasingly

731 severe storms, floods, and drought, leading to the high probability of a refugee crises (Estrada et

732 al., 2017, 2018; Henders et al., 2018). 
734 Unless a way is found to promote environmental protection by "greening" trade (Neumayer,

735 2001; Henders et al., 2018), primate habitat loss and population decline will continue unabated.

736 Since the export of food and nonfood commodities may threaten local food security, human

737 safety, and political stability $(F A O, 2019)$, a balance needs to be achieved that promotes a

738 reduction in global market demands and takes into consideration the needs of primate-range

739 countries to develop their internal economies, to ensure food security for their expanding human

740 populations, and to protect their biodiversity (Estrada et al., 2017). It has been suggested that

741 corporations marketing products that contain tropical forest-risk commodities should add

742 environmental costs to products so that there is a continuous renewal of resources dedicated to

743 improving conservation and restoring natural habitats (Butler \& Laurance, 2008). From our

744 analysis of forest-risk commodity trade data it is notable that while 55 primate-range countries

745 were identified as exporters of these commodities in $2016,95 \%$ of the exports were purchased by

746 only 10 importing nations, suggesting an unsustainable pattern of over-consumption, particularly

747 by China and the US. Action taken by importing countries, such as environmentally-friendly

748 policies - for example, banning illegal timber purchases by the EU $(E U, 2010)$, the EU

749 resolution on palm oil production and deforestation (EP, 2017), and the Amsterdam Declaration

750 to remove deforestation from food and non-food commodity chains (Amsterdam Declaration,

751 2015) — embody important and constructive "green" changes that need to be adopted by the US,

752 China, and other major importers of forest-risk commodity products from primate-range regions

753 (Fig. 17).

754

755 Because demand for products by more affluent and more developed nations can lead to

756 detrimental environmental pressures in primate-rich and resource-rich regions, countries that are 
757 major importers of agricultural and natural resource products from primate-range nations must

758 become active sponsors of, and contributors to, habitat conservation efforts in exporting

759 countries. Sponsoring an increase in land devoted to protected areas, which can improve human

760 well-being for people living near them (Naidoo et al., 2019), contributing to improved

761 conservation management, promoting community-managed forests, and strict adherence to laws

762 and policies that integrate forest protection and commodity production, are all essential actions

763 that can support biodiversity and the people who live in primate-habitat countries (Porter-

764 Bolland et al., 2012; Sharif \& Saha, 2017) (Fig. 13). Importing countries can actively support the

765 regeneration of agricultural land and pasture to secondary forests as an important conservation

766 measure (Chaudhary \& Brown, 2017). In short, a stronger worldwide effort at regulating the

767 negative impact of unsustainable commodity trade in primate-range regions is critically needed

768 (Henders et al., 2018). Because the world's agricultural production and supply chains are

769 controlled by a relatively small number of international corporations (e.g., Cargill, Monsanto,

770 BASF, Dow, Syngenta, and DuPont) that are chartered in consumer nations that produce food in

771 the global south and then exported to other countries for processing and consumption (EcoNexus,

772 2013), ethical responsibility needs to be borne by these corporations. The rise of industrial

773 agriculture (including beef production) has been closely linked to the global seed and

774 agrochemical industries, and this has led to a multitude of environmental problems including the

775 degradation and destruction of ecosystems, a major decline in insect biodiversity, the expanded

776 use of polluting and toxic agrochemicals, and the loss of agricultural biodiversity that threatens

777 sustainable agriculture (Clapp, 2017, 2019; Sánchez-Bayo \& Wyckhuys, 2019). A similar

778 situation has accrued over decades with the extraction and trade of fossil fuels, where a few

779 corporations including ExxonMobil, Chevron, Shell, BP, ConocoPhillips, Peabody 
780 Energy, Consol Energy, and Arch Coal have controlled oil and gas production and distribution

781 worldwide, and disproportionately contributed to the devastating effects of climate change (UCS,

782 2018). The mining of metals and minerals also is controlled by a few companies among which

783 the most dominant are Fresnillo, AngloAmerican, Newmont Mining, Barrick Gold, Coal India,

784 and China Shenhua Energy (https://www.miningglobal.com/top10/top-10-mining-companies-

785 world).

786 By 2050, the global population is projected to increase from 7.5 billion to 9.3 billion and

787 estimates are that food production will need to increase from the current 8.4 billion tonnes to

788 almost 13.5 billion tonnes a year $(F A O, 2014)$. Much of this growth in the human population will

789 take place in primate-range countries, where populations are projected to increasing from 5.1

790 billion to 7.3 billion (Fig. S7A in Estrada et al., 2017). A major sustainability challenge is to

791 meet global nutritional needs through a healthier diet, and to provide food security for the

792 world's human population while reducing the environmental impacts of the burning of fossil

793 fuels, deforestation, desertification, climate change, and water and air pollution (Davila \&

794 Dyball, 2018; Willett et al., 2019). Achieving that level of production from a depleted natural

795 resource base will require an expanded and accelerated effort to transition to sustainable

796 agriculture to ensure world food security, to provide economic opportunities, and to protect the

797 ecosystem services on which agriculture depends (FAO, 2014; FAO, 2017, 2018a, 2019; Willett

798 et al., 2019).

799

Insert Figure 17 about here

800 Although the goals of commodity-driven exporting countries may be to improve their economies

801 and to meet the nutritional and socioeconomic needs of their populations, despite considerable

802 year-to-year increases in revenue derived from agricultural and nonagricultural exports in 
803 primate-range regions, millions of their citizens remain poor, undernourished, and

804 undereducated, and lack access to quality healthcare (World Bank, 2018; Willett et al., 2019).

805 Given the rapid pace and large scale at which forests have been cleared in most primate-range

806 countries, promoting "sustainable intensification" of agriculture on already cleared land would

807 increase production and may help to forestall further land conversion (Carlson et al., 2018). In

808 addition, connecting farmers who are small landholders with international commercial

809 agricultural entities, may also bring direct economic benefits to the rural poor, as long as their

810 land is protected from debt or confiscation (Goldsmith \& Cohn, 2017). However, intensification

811 of agriculture that increases yields will not reduce global hunger as long as a small number of

812 consumer nations distantly located from production areas continue to over-consume and waste

813 food and other commodities. There needs to be a sustained global effort to increase food security

814 in areas of the world where the hungry live, using eco-effective methods that encourage the

815 sustainable productivity of multiple ecosystem services, reduce greenhouse gas emissions, and

816 protect natural biodiversity (Chaudhary \& Mooers, 2018; Keating et al., 2010; Smith et al.,

817 2019). There is compelling evidence that greater powers of decision making by eco-friendly

818 agricultural practices owned by small landholders who are sensitive to local markets and

819 conditions, rather than profit maximizing large-scale industrial agribusiness, is key to food

820 security in developing nations (Runting et al., 2015; Tscharntke et al., 2012). In reality, global

821 commodity resource extraction is predicted to surge from $85 \mathrm{bn}$ tons today to $186 \mathrm{bn}$ by 2050

822 (Resourcetrade.Earth, 2019) and this also will importantly contribute to critical losses of

823 biodiversity, including primates, to the loss of ecosystem services and to huge volumes of GHGs,

824 resulting from the destruction of valuable carbon sinks and from energy-intensive processing

825 (Chaudhary \& Mooers, 2018; Willett et al., 2019). 
827 There is no doubt that additional research is required to examine the role of local and global

828 market demands on primate conservation, including studies to evaluate the extent to which the

829 reduction of land for purposes of agricultural conversion and nonfood resource extraction benefit

830 local human and nonhuman primate communities. Given the crises that we face, applying

831 economic tools to consumer nations, such as taxes on consumption and on agricultural resources,

832 accompanied by investment in sustainable agri-environmental production and sustainable

833 nonfood resource extraction, are viable alternatives to mitigate the negative impacts of global

834 market demands and of the international commodity trade in primate habitats (Kok et al., 2018;

835 Larrosa et al., 2016). Our assessment of the international commodities trade and over-

836 consumption by a small number of consumer nations suggests that conservation success requires

837 a set of internationally agreed upon sustainable approaches to land productivity and to natural

838 resource extraction to ensure food security, alleviate poverty, and mitigate forest loss and

839 degradation $(F A O, 2019)$. It also underlines the need for a stronger global resolve to regulate the

840 negative impact of unsustainable commodity trade on primate habitats and biodiversity. Such

841 global resolution needs to be matched by a reduction of the world's per capita demand for forest-

842 risk food and non-food commodities from primate-range regions. Primates and their habitats are

843 a vital component of the world's natural heritage and culture. As our closest living relatives,

844 nonhuman primates deserve our full attention, concern, and support for their conservation and

845 survivorship.

846

847 ACKNOWLEDGEMENTS

848 We thank Anthony B Rylands for constructive comments on an early draft of the manuscript.

849 Paul A. Garber is forever grateful to Jennifer A. Garber, Sara A. Garber, and Chrissie McKenney

850 for inspiring him to redirect his efforts to protecting the world's threatened primate populations.

851 Alejandro Estrada is thankful to Erika and Alex for always supporting his interests in primate 
852 research and conservation. We are grateful to Dr. Sarah Bologna for her very useful edits on a

853 final version of this article.

854

855

\section{REFERENCES}

856

Ahrends A, Hollingsworth PM, Ziegler AD, Jefferson M. Fox, Huafang C, Yufang S,

857

858

859

860 Jianchu X. 2015. Current trends of rubber plantation expansion may threaten biodiversity and livelihoods. Global Environmental Change 34:48-58.

\section{Alamgir M, Campbell MJ, Sloan S, Goosem M, Clements GR, Mahmoud MI, Laurance W}

861

862

863

864

865

866

867

868

869

870

871

872

873

874

875

876

877

878

879

880 F. 2017. Economic, socio-political and environmental risks of road development in the tropics. Current Biology 27(20):R1130-R1140.

Alamgir M, Campbell MJ, Sloan S, Suhardiman A, Supriatna J, Laurance WF. 2019. Highrisk infrastructure projects pose imminent threats to forests in Indonesian Borneo. Scientific Reports, 9(140) Available at https://rdcu.be/bgVvc.

Alisjahbana AS, Busch JM. 2017. Forestry, forest fires, and climate change in Indonesia. Bulletin of Indonesian Economic Studies 53(2):111-136 DOI 10.1080/00074918.2017.1365404.

Alvarez-Berríos N. L., T. Mitchell Aide. 2015. Global demand for gold is another threat for tropical forests. Environmental Research Letters. 10(1):e014006 DOI 10.1088/17489326/10/1/014006.

Anderson K. 2010. Globalization's effects on world agricultural trade, 1960-2050. Philosophical Transactions of the Royal Society B 365:3007-3021.

Ascensão F, Fahrig L, Clevenger AP, Corlett RT, Jaeger JAG, Laurance WF, Pereira HM. 2019. Environmental challenges for the Belt and Road Initiative. Nature DOI:

881

882

883

884

Asner GP, Llactayo W, Tupayachi R, Ráez Luna E. 2013. Elevated rates of gold mining in the Amazon revealed through high-resolution monitoring. Proceedings of the National

885

886

887 Academy of Sciences of the United States of America 110:18454-18459. doi/10.1073/pnas.1318271110

Barrett MA, Brown JL, Junge RE, Yoder AD. 2013. Climate change, predictive modeling and lemur health: assessing impacts of changing climate on health and conservation in infrastructure threaten forest cover and community rights. Proceedings of the National Academy of Sciences of the United States of America 115(52):13164-3173 Doi.org/10.1073/pnas.1812505115 
898 Beckman J, Sands RD, Riddle AA, Lee T, Walloga JM. 2017. International Trade and

899

900

901

902

903

904

905

906

907

908

909

910

911

912

913

914

915

916

917

918

919

920

921

922

923

924

925

926

927

928

929

930

931

932

933

934

935

936

937

938

939

940

941

942

943

Deforestation: Potential Policy Effects via a Global Economic Model, ERR-229, U.S.

Department of Agriculture, Economic Research Service. Available at

https://ageconsearch.umn.edu/record/262185/files/err-229.pdf?subformat=pdfa

Bloomberg, 2018. Choking on our harvest: Threats loom over global food trade. Available at https://www.bloomberg.com/graphics/2018-foodtrade-chokepoints/ 90 Reuters.

Bettina R. 2015. Trade rules and food security. GiZ, Federal Ministry for Cooperation and Development. Germany. Available at https://www.giz.de/expertise/downloads/giz2015-enStudy_Trade_rules_and_food_security.pdf

Brown RM, Weghorst JA, Olson KV, Duya MR, Barley AJ, Duya MV, Shekelle M, NeriArboleda I, Esselstyn JA, Dominy NJ, Ong PS, Moritz GL, Luczon A, Diesmos ML, Diesmos AC. 2014. Conservation genetics of the Philippine tarsier: cryptic genetic variation restructures conservation priorities for an island archipelago primate. PLoS One 199(8):e104340. Doi: 10.1371/journal.pone.0104340.

Chaudhary A, Brooks TM. 2017. National Consumption and Global Trade Impacts on Biodiversity. World Development. Available at https://doi.org/10.1016/j.worlddev.2017.10.012

Chaudhary A, Mooers AO. 2018. Terrestrial Vertebrate Biodiversity Loss under Future Global Land Use Change Scenarios. Sustainability 10,2764; Doi:10.3390/su10082764www.

Clapp J. 2015. Food security and international trade. Unpacking disputed narratives.

Background paper prepared for The State of Agricultural Commodity Markets 2015-16. Food and Agriculture Organization of the United Nations. Available at http://www.fao.org/3/ai5160e.pdf

Clapp J. 2017. Capital Markets: Investors Care About Growth - Not about the Growers. In: Agrifood Atlas: Facts and Figures about the Corporations that Control What We Eat, Brussels: Heinrick Böll Foundation, Rosa Luxemburg Foundation and Friends of the Earth Europe, 38-39. Available at http://www.foeeurope.org/sites/default/files/agriculture/2017/agrifood_atlas.pdf.

Clapp J. 2019. Mega-Mergers on the Menu: Corporate Concentration and the Politics of Sustainability in the Global Food System. Global Environmental Politics 8(2):12-33; Tthe Massachusetts Institute of Technology. Available at https://doi.org/10.1162/glep_a_00454

Cottrell RS, Nash KL, Halpern BS, Remenyi TA, Corney SP, Fleming A, Fulton EA, Hornborg S, Johne A, Watson RA, Blanchard JL. 2019 . Food production shocks across land and sea. Nature Sustainability 2:130-137. https://doi.org/10.1038/s41893-018-0210-1

Curtis, Philip G., Christy M. Slay, Nancy L. Harris, Alexandra Tyukavina, Matthew C. Hansen. 2018. Classifying drivers of global forest loss. Science 361:1108-1111.

PeerJ reviewing PDF | (2019:03:35624:1:2:NEW 24 Apr 2019) 
944

945

946

947

948

949

950

951

952

953

954

955

956

957

958

959

960

961

962

963

964

965

966

967

968

969

970

971

972

973

974

975

976

977

978

979

980

981

982

983

984

985

986

987

D'Odorico P, Laio F. 2014. Feeding humanity through global food trade. Earth's Future 2(9). Available at: https://www.researchgate.net/publication/264675389_Feeding_humanity_through_ global_food_trade

Davila, Federico; Dyball, Robert. 2018. Food systems and human ecology. In: Ariane K, editor. Sustainability Science. Edited by. ROUTLEDGE in association with GSE Research. , p 183-210. Available at: https://doi.org/10.9774/GLEAF.9781315620329_11

Delgado C. 2005. Rising demand for meat and milk in developing countries: implications for grasslands-based livestock production. In: McGilloway DA, editor. Grassland: a global resource. The Netherlands: Wageningen Academic Publishers. 29-39.

Duffy R. 2007. Gemstone mining in Madagascar: Transnational networks, criminalisation and global integration. Journal of Modern African Studies 45:185-206.

EcoNexus. 2013. Agropoly - A handful of corporations control world food production. Berne Declaration (DB) \& EcoNexus, EvB: Dienerstrasse 12, Postfach, 8026 Zürich, Switzerland. Available at

https://www.econexus.info/sites/econexus/files/Agropoly_Econexus_BerneDeclaration.pdf

Edwards DP, Sloan S, Weng L, Dirks P, Sayer J, Laurance WF. 2014. Mining and the African environment. Conservation Letters 7(3):302-311 DOI 10.1111/conl.12076.

Erasmus H., Benjamin O., Ofori Y., Attuquayefio DK. 2018. The secondary impact of mining on primates and other medium to large mammals in forest reserves in southwestern Ghana. The Extractive Industries and Society 5(1):114-121.

Estrada A, Garber PA, Rylands AB, Roos C, Fernandez-Duque E, Di Fiore A, Nekaris KAI, Nijman V, Heymann EW, Lambert JE, Rovero F, Barelli C, Setchell JM, Gillespie TR, Mittermeier RA, Arregoitia LV, Guinea M, Gouveia S, Dobrovolski R, Shanee S, Shanee N, Boyle SA, Fuentes A, MacKinnon KC, Amato KR, Meyer ALS, Wich S, Sussman RW, Pan R, Kone I, Li B. 2017. Impending extinction crisis of the world's primates: why primates matter. Science Advances 3:e1600946.

Estrada A, Garber PA, Mittermeier RA, Wich S, Gouveia S, Dobrovolski R, Nekaris KAI, Nijman V, Rylands AB, Maisels F, Williamson EA, Bicca-Marques JC, Fuentes A, Jerusalinsky L, Johnson S, Rodriguez de Melo F, Oliveira L, Schwitzer C, Roos C, Cheyne SM, Kierulff MCM, Raharivololona B, Talebi M, Ratsimbazafy J, Supriatna J, Boonratana R, Wedana M, Setiawan A. 2018. Primates in peril: the significance of Brazil, Madagascar, Indonesia and the Democratic Republic of the Congo for global primate conservation. PeerJ 6:e4869; DOI 10.7717/peerj.4869 
988

989

990

991

992

993

994

995

996

997

998

999

1000

1001

1002

1003

1004

1005

1006

1007

1008

1009

1010

1011

1012

1013

1014

1015

1016

1017

1018

1019

1020

1021

1022

1023

1024

1025

1026

1027

1028

1029

1030

1031

1032

1033

European Commission. 2013. The impact of EU consumption on deforestation: Comprehensive analysis of the impact of EU consumption on deforestation. doi: 10.2779/822269. Available at http://ec.europa.eu/environment/forests/pdf/1.\%20Report\%20analysis\%20of\%20impact.pdf

Fader M, Gerten D, Thammer M, Heinke J, Lotze-Campen H, Lucht W, Cramer W. 2011. Internal and external green-blue agricultural water footprints of nations, and related water and land savings through trade. Hydrology and Earth System Sciences 15:1641-1660.

Fader M, Gerten D, Krause M, Lucht W, Cramer W. 2013. Spatial decoupling of agricultural production and consumption: Quantifying dependence of countries on food imports due to domestic land and water constraints. Environmental Research Letters 8 art 014046). Available at https://iopscience.iop.org/article/10.1088/1748-9326/8/1/014046/pdf

Fan PF, Fei HL, Luo AD. 2014. Ecological extinction of the critically endangered northern white-cheeked gibbon Nomascus leucogenys in China. Oryx 48:52-55.

FAO. 2014. Building a common vision for sustainable food and agriculture: principles and approaches. Food and Agriculture Organization of the United Nations. Rome, 2014. Available at http://www.fao.org/3/a-i3940e.pdf

FAO. 2017. Strategic work of FAO for strategic programme to make agriculture, forestry and fisheries more productive and sustainable food and agriculture. Available at http://www.fao.org/3/a-i6488e.pdf

FAO. 2018a. Sustainable agriculture. Available at http://www.fao.org/sustainable-developmentgoals/overview/fao-and-the-post-2015-development-agenda/sustainable-agriculture/en/

FAO. 2018b. The State of Agricultural Commodity Markets 2018. Agricultural trade, climate change and food security. Food and Agriculture Organization of the UN. Rome. Available at http://www.fao.org/3/I9542EN/i9542en.pdf

FAO. 2019. The State of the World's Biodiversity for Food and Agriculture, J. Bélanger \& D. Pilling, eds. FAO Commission on Genetic Resources for Food and Agriculture Assessments. Rome. 572. Available at http://www.fao.org/3/CA3129EN/CA3129EN.pdf

Finer M, Orta-Martínez, M. 2010. A second hydrocarbon boom threatens the Peruvian Amazon: Trends, projections, and policy implications. Environmental Research Letters, 5, 14012. 10pp, https://doi.org/10.1088/1748-9326/5/1/014012

Finer M, Babbitt B, Novoa S, Ferrarese F, Pappalardo SE, De Marchi M, Saucedo M, Kumar A. 2015. Future of oil and gas development in the western Amazon. Environmental Research Letters 10: 024003. Available at https://iopscience.iop.org/article/10.1088/17489326/10/2/024003

Freedom House. 2019. Democracy in Retreat. Freedom in the World 2019. Available at www.freedomhouse.org. 
1034

1035

1036

1037

1038

1039

1040

1041

1042

1043

1044

1045

1046

1047

1048

1049

1050

1051

1052

1053

1054

1055

1056

1057

1058

1059

1060

1061

1062

1063

1064

1065

1066

1067

1068

1069

1070

1071

1072

1073

1074

1075

1076

1077

1078

1079

Fricko O, Havlik P, Rogelj J, Klimont Z, Gusti M, Johnson N, Kolp P, Strubegger M, Valin H, Amann M, Ermolieva T, Nicklas F, Herrero M, Heyes C, Kindermann G, Krey V, McCollum DL, Obersteiner M, Pachauri S, Rao S. 2017 The marker quantification of the Shared Socioeconomic Pathway 2: A middle-of-the-road scenario for the 21st century. Global Environmental Change 42:251-267.

Fuchs R, Brown C, Cossar F, Henry RC, Rounsevell M. 2019. US-China trade war imperils Amazon rainforest. Nature 567: 451-454.

Fuller TL, Narins TP, Nackoney J, Bonebrake TC, Clee PS, Morgan K, Trochez A, Bocuma Mene D, Bongwele E, Njabo KY, Anthony NM, Gonder MK, Kahn M, Allen WR, Smith TB. 2018. Assessing the impact of China's timber industry on Congo Basin land use change. Area 00:1-10. Royal Geographic Society. Available at https://doi.org/10.1111/area.12469

Gardner TA, Benzie M, Börner J, Dawkins E, Fick S, Garrett R, Godar J, Lake S, Larsen RK, Mardas N, McDermott CL, Meyfroidt P, Osbeck M, Sembres T, Suavet C, Strassburg B, Trevisan A, West C, Wolvekamp P, Grimard A, Persson M. 2018. Transparency and sustainability in global commodity supply chains. World Development. Available at https://doi.org/10.1016/j.worlddev.2018.05.025.

Garcia LC, Ribeiro DB, Oliveira-Roque F, Ochoa-Quintero JM, Laurance WF. 2017. Brazil's worst mining disaster: corporations must be compelled to pay the actual environmental costs. Ecological Applications 27(1):5-9 DOI 10.1002/eap.1461.

Gibbs HK, Rausch L, Munger J, Schelly I, Morton DC, Noojipady P, Soares-Filho B, Barreto P, Micol L, Walker NF. 2015. Brazil's Soy Moratorium. Policy Forum. Science. 347: 377-378. DOI: 10.1126/science.aaa0181.

Gould L, Sauther ML. 2016. Going, going, gone ... Is the iconic ring-tailed lemur (Lemur catta) headed for imminent extirpation? Primate Conservation 30:89-101.

GRASP, IUCN. 2018. Report to the CITES Standing Committee on the Status of Great Apes. United Nations Environment Programme Great Apes Survival Partnership, Nairobi, and International Union for Conservation of Nature, Gland. Available at https://cites.org/sites/default/files/eng/com/sc/70/E-SC70-52.pdf

\section{Harfoot MBJ, Tittensor DP, Knight S, Arnell AP, Blyth S, Brooks S, Butchart SHM,} Hutton J, Jones MI, Kapos V, Scharlemann JPW, Burgess ND. 2017. Present and future biodiversity risks from fossil fuel exploitation. Conservation Letters Available at https://doi.org/10.1111/conl.12448

Henchion M, McCarthy M, Resconi VC, Troy D. 2014. Meat consumption: trends and quality matters. Meat Science 98:561-568. 
1080 Henders S, Persson UM, Kastner T. 2015. Trading forests: land-use change and carbon

1081

1082

1083

1084

1085

1086

1087

1088

1089

1090

1091

1092

1093

1094

1095

1096

1097

1098

1099

1100

1101

1102

1103

1104

1105

1106

1107

1108

1109

1110

1111

1112

1113

1114

1115

1116

1117

1118

1119

1120

1121

1122

1123

1124

1125 emissions embodied in production and exports of forest-risk commodities. Environmental Research Letters 10(12):125012 DOI 10.1088/1748-9326/10/12/125012.

Henders S, Ostwald M, Verendel V, Ibisch P. 2018. Do national strategies under the UN biodiversity and climate conventions address agricultural commodity. Land Use Policy 70:580-590.

Hosonuma N, Herold M, De Sy V, DeFries R, Brockhaus M, Verchot L, Angelsen A, Romijn E. 2012. An assessment of deforestation and forest degradation drivers in developing countries Environmental Research Letters 7:1-12.

Howard A. 2016. Blood Diamonds: The Successes and Failures of the Kimberley Process Certification Scheme in Angola, Sierra Leone and Zimbabwe. 15 Washington Univderaity Global Studies Law Review 15(1):137-159. Available at http://openscholarship.wustl.edu/law_globalstudies/vol15/iss1/8

IUCN. 2015. International union for conservation of nature. Habitat Classification Scheme Version, 3, 1 http://www.iucnredlist.org/technical-documents/classification-schemes/habitatsclassification-scheme-ver3

IUCN. 2019. International Union for Conservation of Nature. The IUCN Red List of Threatened Species. Version 2018-2. http://www.iucnredlist.org

Kharas H. 2017. The unprecedented expansion of the global middle class an update. The Bookings Institution. Available at https://www.brookings.edu/wpcontent/uploads/2017/02/global_20170228_global-middle-class.pdf

Karstensen J, Peters GP, Andrew RM. 2013. Attribution of CO emissions from Brazilian deforestation to consumers between 1990 and 2010. Environmental Research Letters 8(2):024005. DOI 10.1088/1748-9326/8/2/024005.

Koh LP, Ghazoul J. 2008. Biofuels, biodiversity, and people: understanding the conflicts and finding opportunities. Biological Conservation 141:2450-2460.

\section{Kok MTJ, Alkemade R, Bakkenes M, van Eerdt M, Janse J, Mandryk M, Kram T,} Lazarova T, Meijer J, van Oorschot $M$, Westhoek $H$, van der Zagt $R$, van der Berg $M$, van der Esch S, Prins AG, van Vuuren DP. 2018. Pathways for agriculture and forestry to contribute to terrestrial biodiversity conservation: A global scenario-study. Biological Conservation 221:137-150. DOI 10.1016/j.biocon.2018.03.003

Lambin EF, Meyfroidt P. 2011. Global land use change, economic globalization, and the looming land scarcity. Proceedings of the National Academy of Sciences of the United States of America, 108(9):3465-3472. Doi.org/10.1073/pnas.1100480108. 
1126 Lamy P. 2011. Trade is vital for food security, Lamy tells agricultural economists. Speech to

1127

1128

1129

1130

1131

1132

1133

1134

1135

1136

1137

1138

1139

1140

1141

1142

1143

1144

1145

1146

1147

1148

1149

1150

1151

1152

1153

1154

1155

1156

1157

1158

1159

1160

1161

1162

1163

1164

1165

1166

1167

1168

1169

1170

1171

XIIIth Congress of the European Association of Agricultural Economists, August 30. Zurich. Available at https://www.wto.org/english/news_e/sppl_e/sppl203_e.htm, accessed March 25, 2015.

Lamy P. 2012. Pascal Lamy speaks on the challenge of feeding 9 billion people. Speech at The Economist Conference "Feeding the World", February 8. Geneva. Available at http://www.wto.org/english/news_e/sppl_e/sppl216_e.htm, accessed December 16, 2018.

Lanjouw A. 2014. Extractive Industries and Ape Conservation. In: State of the Apes. H Rainer, A. White, A. Lanjouw, Eds. Arcus/Cambridge Univ. Press. 127-161.

Lanjouw A, Rainer H, White A. 2015. Apes overview, In: State of the Apes Industrial Agriculture and Ape Conservation. H Rainer, A. White, A. Lanjouw, Eds. Arcus/Cambridge Univ. Press. 164-192.

Larrosa C, Carrasco LR, Milner-Gulland E. 2016. Unintended feedbacks: challenges and opportunities for improving conservation effectiveness. Conservation Letters 9(5):316-326 DOI 10.1111/conl.12240.

Lawsom S, Blundell A, Cabarle B, Basik N, Jenkins M, Canby K. 2014. Consumer Goods and Deforestation: An Analysis of the Extent and Nature of Illegality in Forest Conversion for Agriculture and Timber Plantations. Forest Trends Report Series. Available at https://www.forest-trends.org/wp-content/uploads/imported/for168-consumer-goods-anddeforestation-letter-14-0916-hr-no-crops_web-pdf.pdf

Lewis SL, Edwards DP, Galbraith D. 2015. Increasing human dominance of tropical forests. Science 349:827-832.

Li B, Ming Li, Li J, Fan P, Ni Q, Lu J, Zhou X, Long Y, Xu W, Jiang X, Zhang P, Huang Z, Pan R, Gouveia S, Dobrovolski R, Grueter CC, Zhigang, Oxnard C, Groves C, Estrada A, Garber PA. 2018. The primate extinction crisis in China: immediate challenges and a way forward. Biodiversity and Conservation https://doi.org/10.1007/s10531-018-1614-y

Linder JM. 2013. African primate diversity threatened by "new wave" of industrial oil palm expansion. African Primates 8:25-38.

Liu X, Blackburn TM, Song T, Li X, Huang C, Li Y. 2019. Risks of Biological Invasion on the Belt and Road. Current Biology 29:499-505 DOI/10.1016/j.cub.2018.12.036

MacDonald GK, Brauman KE, Shipeng Sun A, Carlson KM, Cassidy ES, Gerber JS, West C. 2015. Rethinking agricultural trade relationships in an era of globalization. BioScience 65:275-289.

Machovina B, Feeley KJ, Ripple WJ. 2015. Biodiversity conservation: the key is reducing meat consumption. Science of the Total Environment 536:419-431.

PeerJ reviewing PDF | (2019:03:35624:1:2:NEW 24 Apr 2019) 
1172

1173

1174

1175

1176

1177

1178

1179

1180

1181

1182

1183

1184

1185

1186

1187

1188

1189

1190

1191

1192

1193

1194

1195

1196

1197

1198

1199

1200

1201

1202

1203

1204

1205

1206

1207

1208

1209

1210

1211

1212

1213

1214

1215

1216
Malhi Y, Gardner TA, Goldsmith GR, Silman MR, Zelazowski P. 2014. Tropical forests in the Anthropocene. Annual Review of the Environmental Resources. 39:125-159.

Mazumder MK. 2014. Diversity, habitat preferences, and conservation of the primates of southern Assam India: The story of a primate paradise. Journal of Asia Pacific Biodiversity 7:347-354.

Meijaard E, Nijman V. 2000. Distribution and conservation of the proboscis monkey (Nasalis larvatus) in Kalimantan, Indonesia. Biological Conservation 92(1):15-24 DOI 10.1016/s00063207(99)00066-x.

Meijaard E, Wich S, Ancrenaz M, Marshall AJ. 2012. Not by science alone: Why orangutan conservationists must think outside the box. Annals of the New York Academy of Science 1249:29-44.

Meyfroidt P, Lambin EF, Erb KH, Hertel TW. 2013. Globalization of land use: distant drivers of land change and geographic displacement of land use. Current Opinion in Environmental Sustainability 5:438-44.

MERICS 2019. Mercator Institute for China Studies. Available at https://www.merics.org/en/bri-tracker

Mielke T, Mielke I. 2018. Global supply, demand and price outlook of oil \& fats in 2018/19. Oil World. Available at https://www.oilworld.biz/t/sample/sample_34.pdf

Moran D, Petersone M, Verones F. 2016. On the suitability of input-output analysis for calculating product-specific biodiversity footprints. Ecological Indicators 60:192-201.

Morgan D, Mundry R, Sanz C, Eyana Ayina C, Strindberg S, Lonsdorf E, Kühl HS. 2018. African apes coexisting with logging: Comparing chimpanzee (Pan troglodytes troglodytes) and gorilla (Gorilla gorilla gorilla) resource needs and responses to forestry activities. Biological Conservation 218:277-286. DOI.org/10.1016/j.biocon.2017.10.026

Muller RD, Muller D, Schierhorn F, Gerold G, Pacheco P.. 2012. Proximate Causes of Deforestation in the Bolivian Lowlands: An Analysis of Spatial Dynamics. Regional Environmental Change 12:445-459.

\section{Naidoo R, Gerkey D, Hole D, Pfaff A, Ellis AM, Golden CD, Herrera D, Johnson K,} Mulligan M, Ricketts TH, Fisher B. 2019. Evaluating the impacts of protected areas on human wellbeing across the developing world. Science Advances 5:eaav3006.

Nantha HS, Tisdell C. 2009. The orangutan-oil palm conflict: Economic constraints and opportunities for conservation. Biodiversity and Conservation 18:487-502. 
1217 Nomuh FD. 2018. Population surveys of forkmarked dwarf lemurs and needleclawed galagos.

1218 Primates 59(4):355-360.

1219

1220

1221

1222

1223

1224

1225

1226

1227

1228

1229

1230

1231

1232

1233

1234

1235

1236

1237

1238

1239

1240

1241

1242

1243

1244

1245

1246

1247

1248

1249

1250

1251

1252

1253

1254

1255

1256

1257

1258

1259

1260

1261
OECD. 2013. The role of food and agricultural trade in ensuring domestic food availability. In OECD. Global food security: challenges for the food and agricultural system. Paris. Available at http://dx.doi.org/10.1787/9789264195363-en. Accessed December 16, 2018.

Oxfam. 2019a. Brazil: extreme inequality in numbers. Oxfam International.

https://www.oxfam.org/en/even-it-brazil/brazil-extreme-inequality-numbers. Last consulted, February 2019.

Oxfam. 2019b. Inequality in Indonesia: millions kept in poverty. Oxfam International. https://www.oxfam.org/en/indonesia-even-it/inequality-indonesia-millions-kept-poverty. Last consulted, February 2019.

Peres CA. 1999. Ground fires as agents of mortality in a Central Amazonian forest. Journal of Tropical Ecology 15(4):535-54.

Peres, C. A. 2001. The fire next time. The potential for a catastrophic blaze threatens the Amazon. Time Magazine, 8 January 2001, 48.

Plumptre AJ, Nixon S, Critchlow R, Vieilledent G, Nishuli R, Kirkby A, WilliamsonEA, Ha II JS, Kujirakwinja D. 2015. Status of Grauer's Gorilla and Chimpanzees in Eastern Democratic Republic of Congo: Historical and Current Distribution and Abundance. New York: Wildlife Conservation Society, Fauna \& Flora International and Institut Congolais pour la Conservation de la Nature. Available at: https://www.sec.gov/comments/statement013117/cl12-1626115-137341.pdf

Porter-Bolland L, Ellis EA, Guariguata MR, Ruiz-Mallén I, Negrete-Yankelevich S, ReyesGarcía V. 2012. Community managed forests and forest protected areas: An assessment of their conservation effectiveness across the tropics. Forest Ecology and Management. 268:617.

Ranganathan J, Vennard D, Waite R, Dumas P, Lipinski B, Searchinger T. 2016. Shifting Diets for a Sustainable Food Future. Working Paper, Installment 11 of Creating a Sustainable Food Future. Washington, DC: World Resources Institute. Available at http://www.worldresourcesreport.org

Remis MJ, Robinson CAJ. 2012. Reductions in primate abundance and diversity in a multiuse protected area: Synergistic impacts of hunting and logging in a Congo Basin forest. American Journal of Primatology 74:602-612.

Reuters 2017. Thousands of soy trucks stranded on swamped Amazon highway in Brazil. March 1st, 2017. Available at: https://www.reuters.com/ article/us-brazil-road-idUSKBN1685AN 
1262 Sánchez-Bayo F, Wyckhuys, KAG. 2019. Worldwide decline of the entomofauna: A review of

1263

1264

1265

1266

1267

1268

1269

1270

1271

1272

1273

1274

1275

1276

1277

1278

1279

1280

1281

1282

1283

1284

1285

1286

1287

1288

1289

1290

1291

1292

1293

1294

1295

1296

1297

1298

1299

1300

1301

1302

1303

1304

1305

1306

1307 its drivers. Biological Conservation 232:8-27.

Smith WK, Nelson E, Johnson JA, Polasky S, Milder JC, Gerber JS, West PC, Siebert S, Brauman KA, Carlson KM, Arbuthnot M, Rozza JP, Pennington DN. 2019. Voluntary sustainability standards could significantly reduce detrimental impacts of global agriculture. Proceedings of the National Academy of Sciences of the United States of America 116 (6):2130-2137 DOI.org/10.1073/pnas.1707812116

Spira C, Kirkby A, Kujirakwinja D, Plumptre AJ. 2017. The socio-economics of artisanal mining and bushmeat hunting around protected areas: Kahuzi-Biega National Park and Itombwe Nature Reserve, eastern Democratic Republic of Congo. Oryx DOI: 10.1017/S003060531600171X.

Stehfest E, Bouwman L, van Vuuren DP, den Elzen MGJ, Eickhout B, Kabat P, 2009. Climate benefits of changing diet. Climate Change 95:83-102.

Strona G, Stringerb SD, Vieilledenta G, Szantoia Z, Garcia-Ulloa J, Wich SA. 2018. Small room for compromise between oil palm cultivation and primate conservation in Africa. Proceedings of the National Academy of Sciences of the United States of America 115(35):8811-8816. DOI/10.1073/pnas.1804775115.

Struebig M J, Fischer M, Gaveau DL, Meijaard E, Wich SA, Gonner C, Sykes R, A. Wilting, Kramer-Schadt S. 2015. Anticipated climate and land-cover changes reveal refuge areas for Borneo's orang-utans. Global Change Biology 21:2891-2904.

The Economist Intelligence Unit. 2018. The Global Food Security Index 2018: Building resilience in the face of rising food-security risks. (C) The Economist Intelligence Unit Limited 2018. Available at

file://C:/Users/aestr/Downloads/EIU\%20Global\%20Food\%20Security\%20Index\%20\%202018\%20Findings\%20\&\%20Methodology.pdf

USDA. 2018. World agricultural production. United States Department of Agriculture. Circular Series. WAP 11-2018. Available at https://apps.fas.usda.gov/psdonline/circulars/production.pdf

USDA-FAS. 2018. Oilseeds: world markets and trade. Washington, DC: US Department of Agriculture-Foreign Agricultural Service. Available at https://apps.fas.usda.gov/psdonline/circulars/oilseeds.pdf; https://www.fas.usda.gov/data/oilseeds-world-markets-and-trade

Van Vuuren, DP, Stehfest E, Gernaat DE, Doelman JC, Van den Berg M, Harmsen M, de Boer HS, Bouwman LF, Daioglou V, Edelenbosch OY, Energy Girod B. 2017. Energy, land-use and greenhouse gas emissions trajectories under a green growth paradigm. Global Environmental Change 42:237-250. 
1308 Vijay V., S. L. Pimm, C. N. Jenkins, S. J. Smith. 2016. The impacts of oil palm on recent deforestation and biodiversity loss. PLOS ONE 11, e0159668.

1310

1311

1312

Voigt M, Wich SA, Ancrenaz M, Meijaard E, Abram N, Banes GL, Campbell-Smith G, d'Arcy L J, Delgado RA, Erman A, Gavea D, Goossens B, Heinicke S, Houghton M, Husson SJ, Leiman A, Llano Sanchez K, Makinuddin, Andrew J. Marshall, Ari Meididit, Jukka Miettinen, Roger Mundry, Musnanda, Nardiyono N, Nurcahyo A, Odom K, Panda A, Prasetyo D, Priadjati A, Purnomo, Rafiastanto A, Russon A, Santika T, Sihite J, Spehar S, Struebig M, Sulbaran-Romero E, Tjiu A, Wells J, Wilson KA., Kühl HS. 2018. Global Demand for Natural Resources Eliminated More Than 100,000 Bornean Orangutans. Current Biology 28:761-769. https://doi.org/10.1016/j.cub.2018.01.053

Warren-Thomas E, Dolman PM, Edwards DP. 2015. Increasing Demand for Natural Rubber Necessitates a Robust Sustainability Initiative to Mitigate Impacts on Tropical Biodiversity. Conservation Letters DOI:10.1111/conl.12170

Wich SA, Garcia-Ulloa J, Kühl HS, Humle T, Lee JSH, Koh LP. 2014. Will oil palm's homecoming spell doom for Africa's great apes? Current Biology 24:1659-1663.

\section{Willett WRJ, Loken B, Springmann M, Lang T, Vermeulen S, Garnett T, Tilman D,} DeClerck F, Wood A, Jonell M, Clark M, Gordon LJ, Fanzo J, Hawkes C, Zurayk R, Rivera JA, De Vries W, Sibanda LM, Afshin A, Chaudhary A, Herrero M, Agustina R, Branca F, Lartey A, Fan S, Crona B, Fox E, Bignet V, Troell M, Lindahl T, Singh S, Cornell SE, Reddy K S, Narain S, Nishtar S, Murray CJL. 2019. Food in the Anthropocene: the EAT-Lancet Commission on healthy diets from sustainable food systems. The Lancet http://dx.doi.org/10.1016/S0140-6736(18)31788-4

World Bank. 2012. Global Monitoring Report 2012. Food prices, nutrition, and the Millennium Development Goals. Washington, DC. Available at https://openknowledge.worldbank.org/handle/10986/6017

World Bank. 2015. Trade policy and food security. 2015. Available at https:// openknowledge.worldbank.org/handle/10986/20537

World Bank, 2018. Commodity markets outlook. Available at http://www.worldbank.org/commodities

Zalles V, Hansen MC, Potapov PV, Stehman SV, Tyukavina A, Pickens A, Song XP, Adusei B, Okpa C, Aguilar R, John N, Chavez S. 2019. Near doubling of Brazil's intensive row crop area since 2000. Proceedings of the National Academy of Sciences of the United States of America 116 (2):428-435. DOI.org/10.1073/pnas. 1810301115 


\section{Table $\mathbf{1}$ (on next page)}

Deforestation per year (loss of $>30 \%$ tree-canopy cover) based on remote sensing for the period 2001 to 2017 for the four primate range regions under consideration.

Also shown is the rate of forest loss for each region and the average percent of permanent forest loss caused by commodity-driven forest loss for 2001 to 2015. Shown at the bottom is the total loss in millions of ha for the four regions. Regions are ranked by the magnitude of tree-cover loss between 2001 and 2017. 
1 Table 1:

2 Deforestation per year (loss of $>\mathbf{3 0} \%$ tree-canopy cover) based on remote sensing for the 3 period 2001 to 2017 for the four primate range regions under consideration. Also shown is 4 the rate of forest loss for each region and the average percent of permanent forest loss caused by 5 commodity-driven forest loss for 2001 to 2015. Shown at the bottom is the total loss in millions 6 of ha for the four regions. Regions are ranked by the magnitude of tree-cover loss between 2001 7 and 2017.

\begin{tabular}{|l|c|c|c|}
\hline Region (n= countries) & $\begin{array}{c}\text { Tree cover loss } \\
2001-2017 \\
\text { (million ha) }\end{array}$ & $\begin{array}{c}\text { Rate } \\
(\mathrm{n}=17 \text { years) } \\
\text { (million ha/yr) }\end{array}$ & $\begin{array}{c}\text { Average \% } \\
\text { commodity-driven } \\
\text { deforestation per } \\
\text { region 2001-2015 }\end{array}$ \\
\hline Neotropics (n=20) & 83.5 & 4.91 & 26 \\
\hline Southeast Asia ( $\mathrm{n}=12)$ & 54.3 & 3.19 & 47 \\
\hline Africa $(\mathrm{n}=35)$ & 38.5 & 2.29 & 26 \\
\hline South Asia $(\mathrm{n}=7)$ & 1.9 & 0.11 & \\
\hline Total $(2001-2017)$ & 178.8 million ha & $\begin{array}{c}\text { Four regions } \\
10.52 \text { million } \\
\text { ha/yr }\end{array}$ & \\
\hline
\end{tabular}

Note: Based on remote sensing, Global Forest Watch (GWF) has classified five principal causes of forest loss in the world: forestry (26\%); shifting agriculture (24\%); wildfire (23\%); commodity-driven deforestation and urbanization $(27 \%)$. The last two are consider as drivers of permanent deforestation. Deforestation is measured by GFW as loss of $>30 \%$ tree canopy cover. 


\section{Table 2 (on next page)}

Top 15 countries with the greatest number of primate species threatened with extinction (2016).

The total number of primate species threatened with extinction (\#threatened) are allocated to the negative effects of conversion of forested land for purposes of forestry, grazing, and agriculture (see Chaudhary \& Mooers, 2018 for additional details). * 
1 Table 2:

2 Top 15 countries with the greatest number of primate species threatened with extinction

3 (2016). The total number of primate species threatened with extinction (\#threatened) are

4 allocated to the negative effects of conversion of forested land for purposes of forestry, grazing,

5 and agriculture (see Chaudhary \& Mooers, 2018 for additional details). The number of primate

6 species per country and IUCN status was taken from Estrada et al., 2017, except for those of

7 China which was taken from Li et al 2018.

8

9

\begin{tabular}{|c|c|c|c|c|c|c|}
\hline Country & \# species & $\begin{array}{c}\# \\
\text { threatened }\end{array}$ & $\begin{array}{c}\% \\
\text { threatened }\end{array}$ & $\begin{array}{c}\% \\
\text { threatened } \\
\text { due to } \\
\text { Forestry }\end{array}$ & $\begin{array}{c}\% \\
\text { threatened } \\
\text { due to } \\
\text { Grazing }\end{array}$ & $\begin{array}{c}\% \\
\text { threatened } \\
\text { due to } \\
\text { Agriculture }\end{array}$ \\
\hline Brazil & 116 & 39 & 34 & 15 & 46 & 27 \\
\hline Madagascar & 103 & 90 & 87 & 13 & 76 & 10 \\
\hline Indonesia & 56 & 38 & 68 & 43 & 11 & 43 \\
\hline Peru & 44 & 11 & 25 & 21 & 38 & 20 \\
\hline Colombia & 37 & 18 & 49 & 21 & 64 & 11 \\
\hline Cameroon & 32 & 9 & 28 & 38 & 18 & 37 \\
\hline Nigeria & 26 & 11 & 42 & 27 & 31 & 35 \\
\hline China & 25 & 20 & 80 & 30 & 46 & 18 \\
\hline Vietnam & 22 & 19 & 86 & 37 & 6 & 52 \\
\hline India & 22 & 12 & 55 & 44 & 5 & 41 \\
\hline Malaysia & 20 & 14 & 70 & 52 & 4 & 40 \\
\hline Laos & 18 & 15 & 83 & 51 & 7 & 37 \\
\hline Thailand & 18 & 11 & 61 & 31 & 5 & 58 \\
\hline Myanmar & 17 & 11 & 65 & 59 & 3 & 34 \\
\hline Cambodia & 10 & 9 & 90 & 30 & 9 & 56 \\
\hline
\end{tabular}




\section{Figure 1}

Numbers in black indicate species richness in the main regions where primates are naturally found: the Neotropics, Africa (mainland Africa and Madagascar), south Asia and southeast Asia.

The country colors indicate the number of species in each country. In Africa, Madagascar stands out with its rich and endemic primate fauna (the lemurs). The range of Papio hamadryas extends from mainland Africa into Asia with small populations present in Saudi Arabia and Yemen.

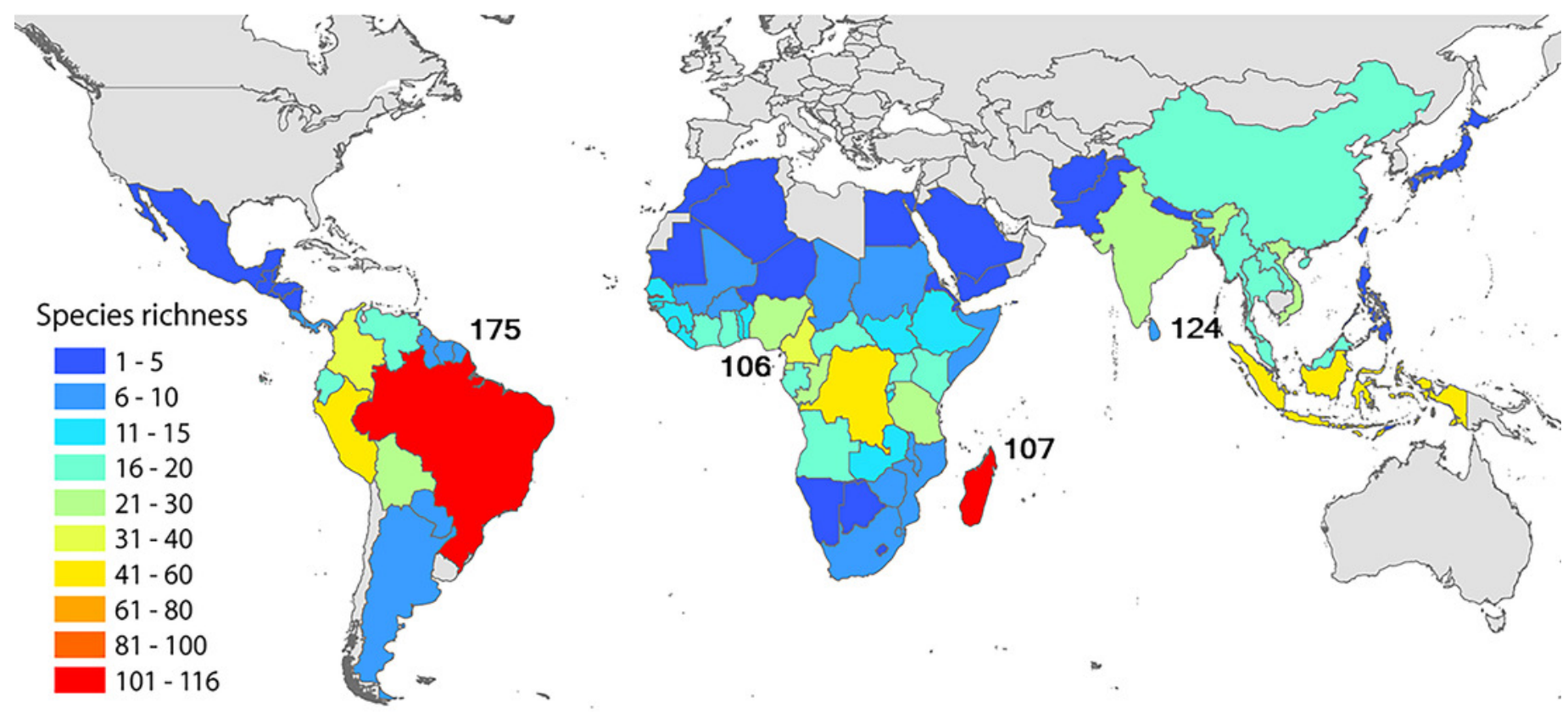


Figure 2

Forest loss (reduction in $>30 \%$ tree canopy cover) for 2001-2017 (orange bars) and percent of commodity-driven forest loss (permanent deforestation) for 2001-2015 (blue area).

Primate range countries in (A) the Neotropics, (B) Africa (includes Madagascar), (C) Southeast Asia and (D) South Asia.
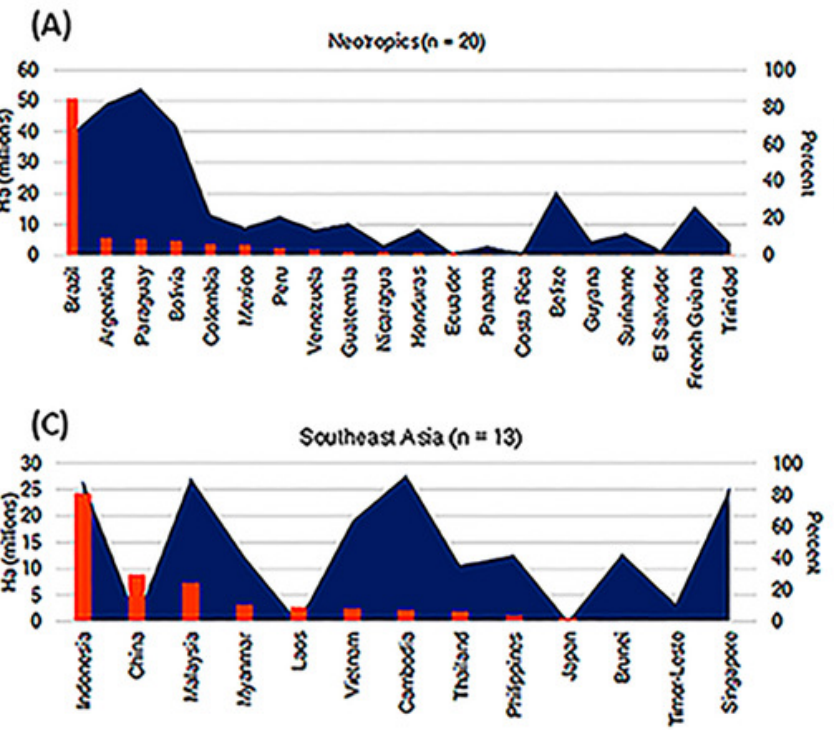

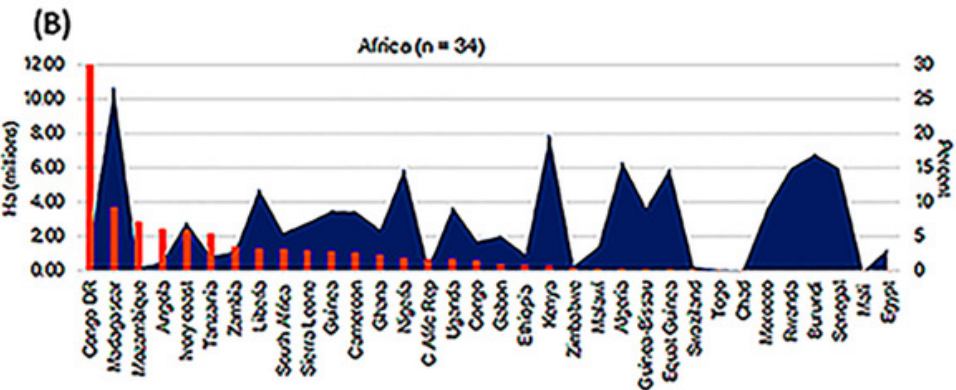

(D)

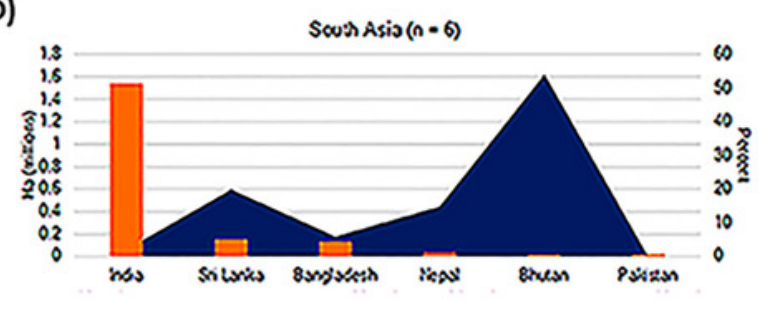

- \% commodity deforestation 2001-2015 a Forest loss (Mha) 2001-2017 


\section{Figure 3}

Commodity exports.

(A) Growth of commodity exports between 2000 and 2016 by countries in primaterange regions. Exports refer to all trading parterns (left side of figure) and to countries that comprise the G-20 group (right side of figure). Source: resource trade.earth of Chatham House. (B) Commodities exported in $\mathbf{2 0 1 6}$ by countries in each primate range region. Beef is considered an agricultural commodity as its large-scale production requires the conversion of large areas of forest pasture. 
A 500
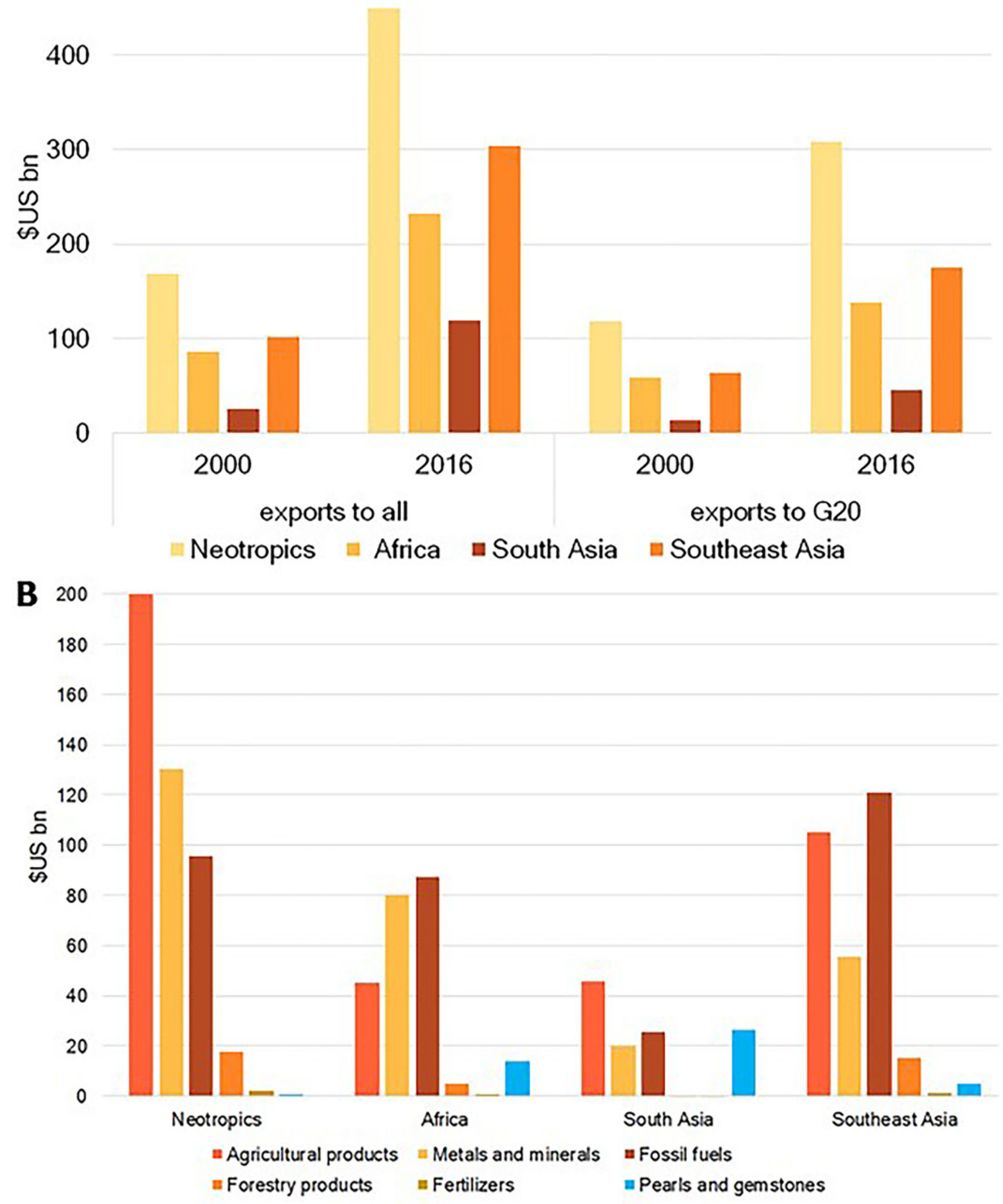
Figure 4

Growth in the export of (A) soybeans, (B) oil palm, (C) natural rubber and (D) beef that led to permanent deforestation in primate-range regions between 2000 and 2016.

Other regions in (A) and (D) refer to Africa, South Asia and Southeast Asia and in (B) and (C) to the Neotropics, Africa, and South Asia.

(A) Soybeans: exports to all countries

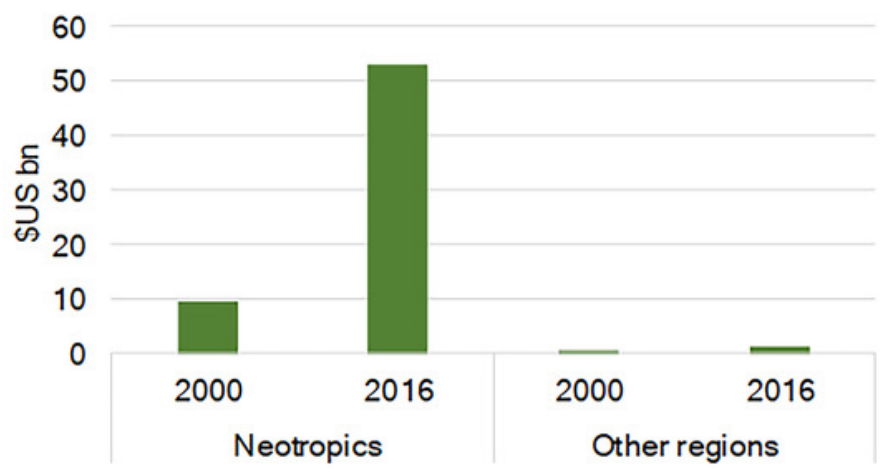

(C) Rubber: exports to all countries

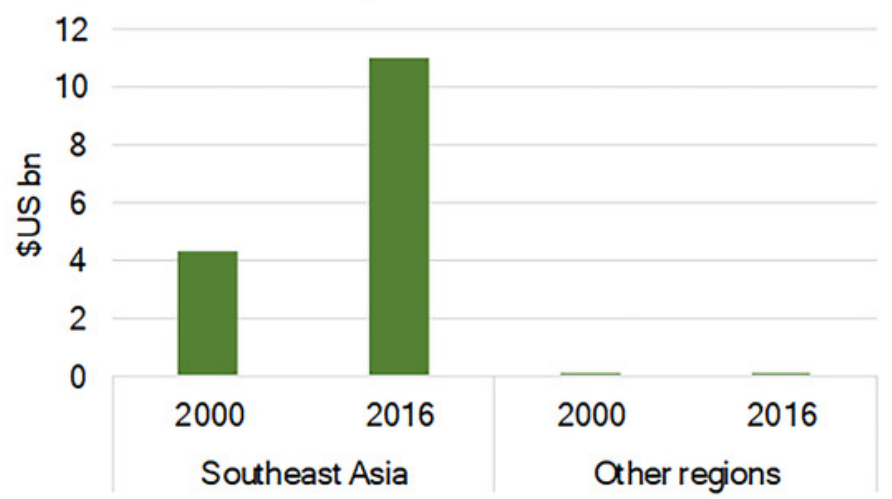

(B) Oil palm: exports to all countries

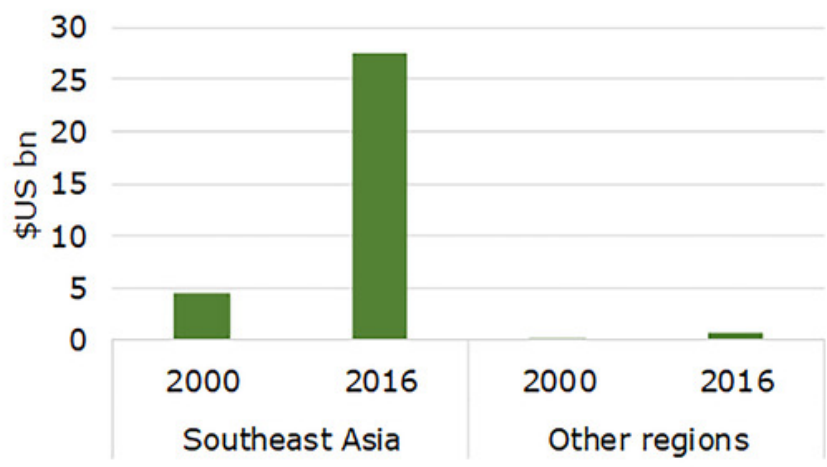

(D) Beef. exports to all countries

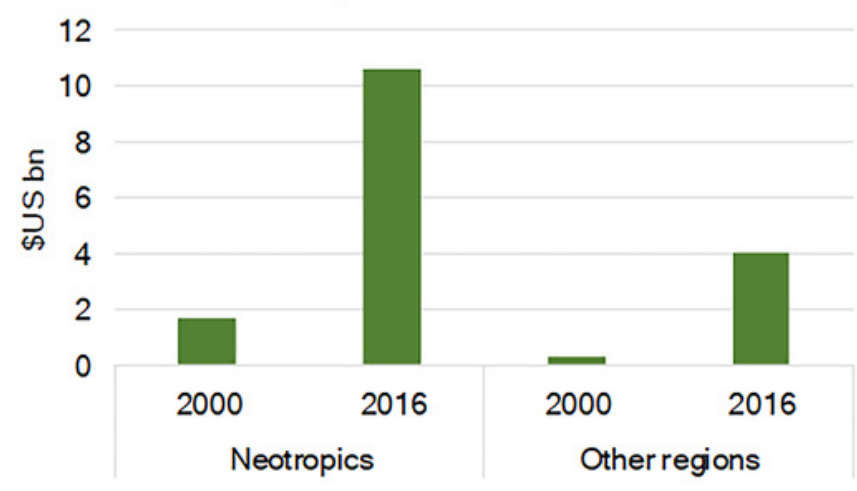


Figure 5

Increase in the area of land dedicated to the production of (A) soybean, (B) oil palm, (C) natural rubber and (D) cattle stocks.

These increases led to permanent deforestation in primate-range regions between 1960 and 2016.
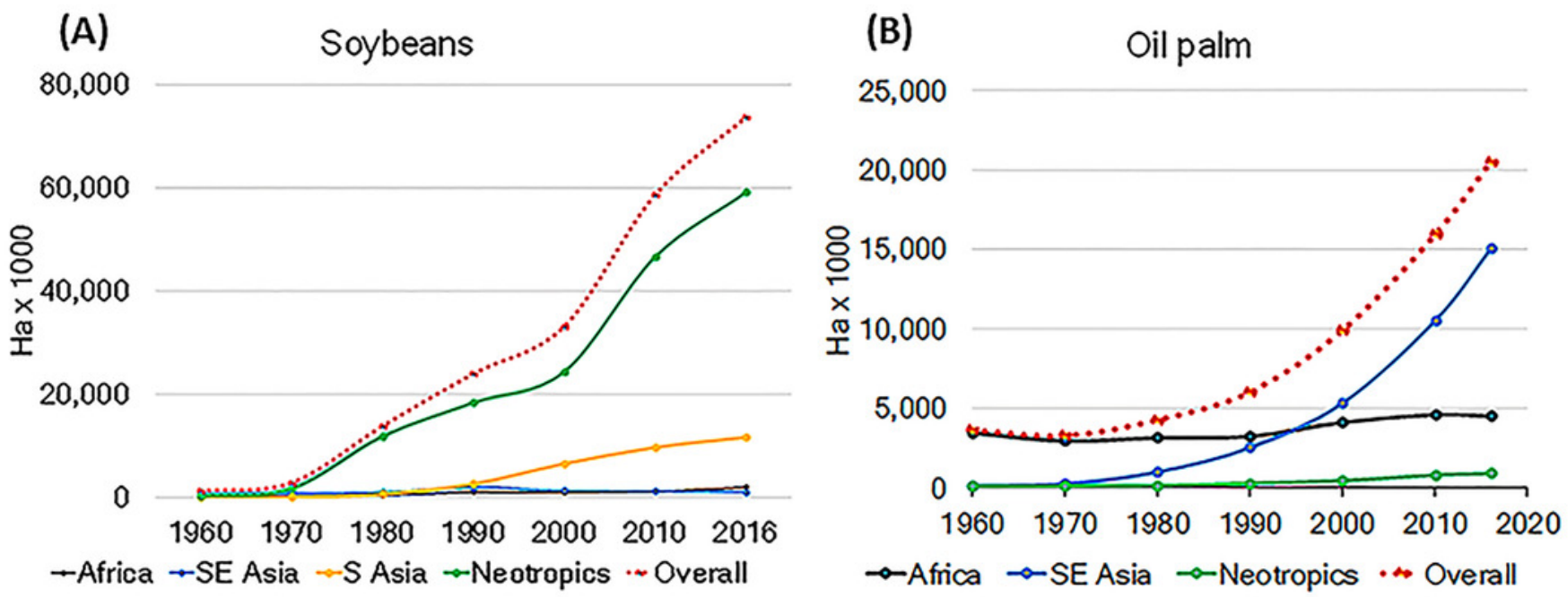

\section{(C) Rubber}
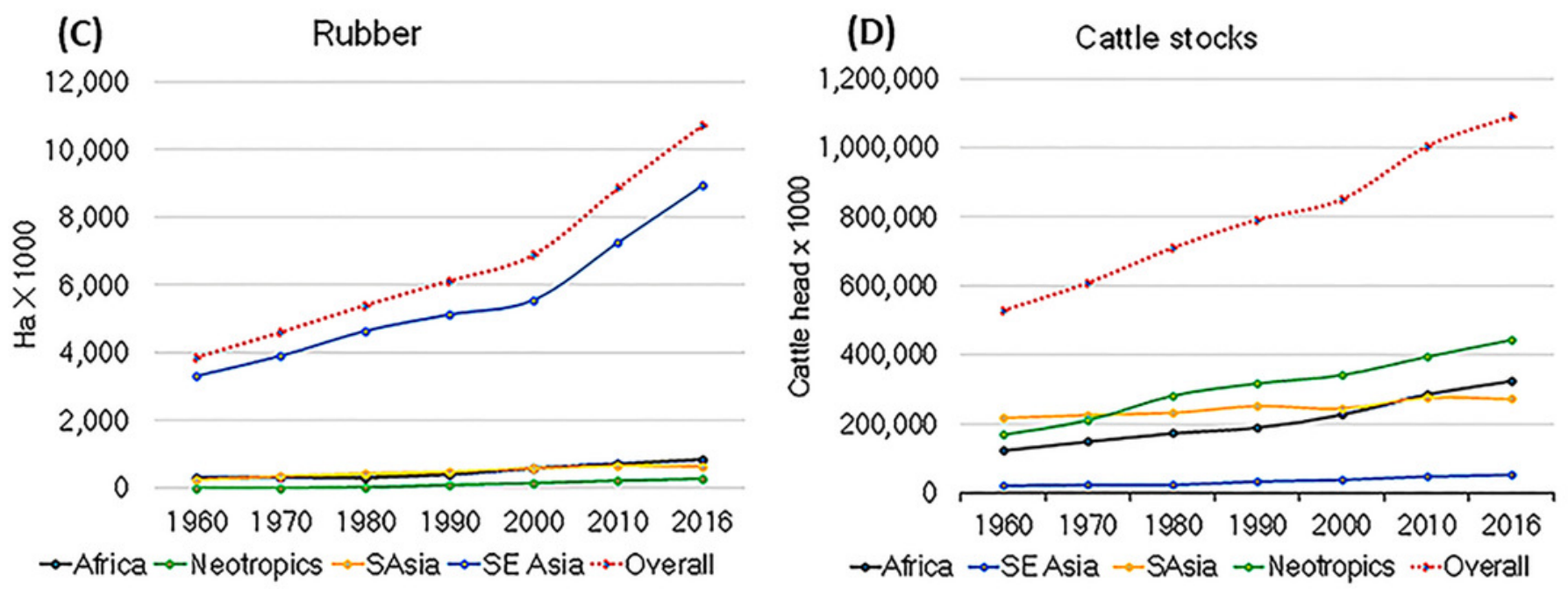


\section{Figure 6}

Trade flow diagrams for the top exporter and importer countries of four commodities that resulted in permanent deforestation in each primate-range region in 2016. Soybeans (A, B), Oil Palm (C, D).

Numbers on the flow diagrams indicate the amount in US\$ bn of trade for each country. For exports and imports, the trade flows show on the left the accumulated US\$ bn for each region and for the countries involved. The width of the connecting flows is proportional to the value exported or imported. 


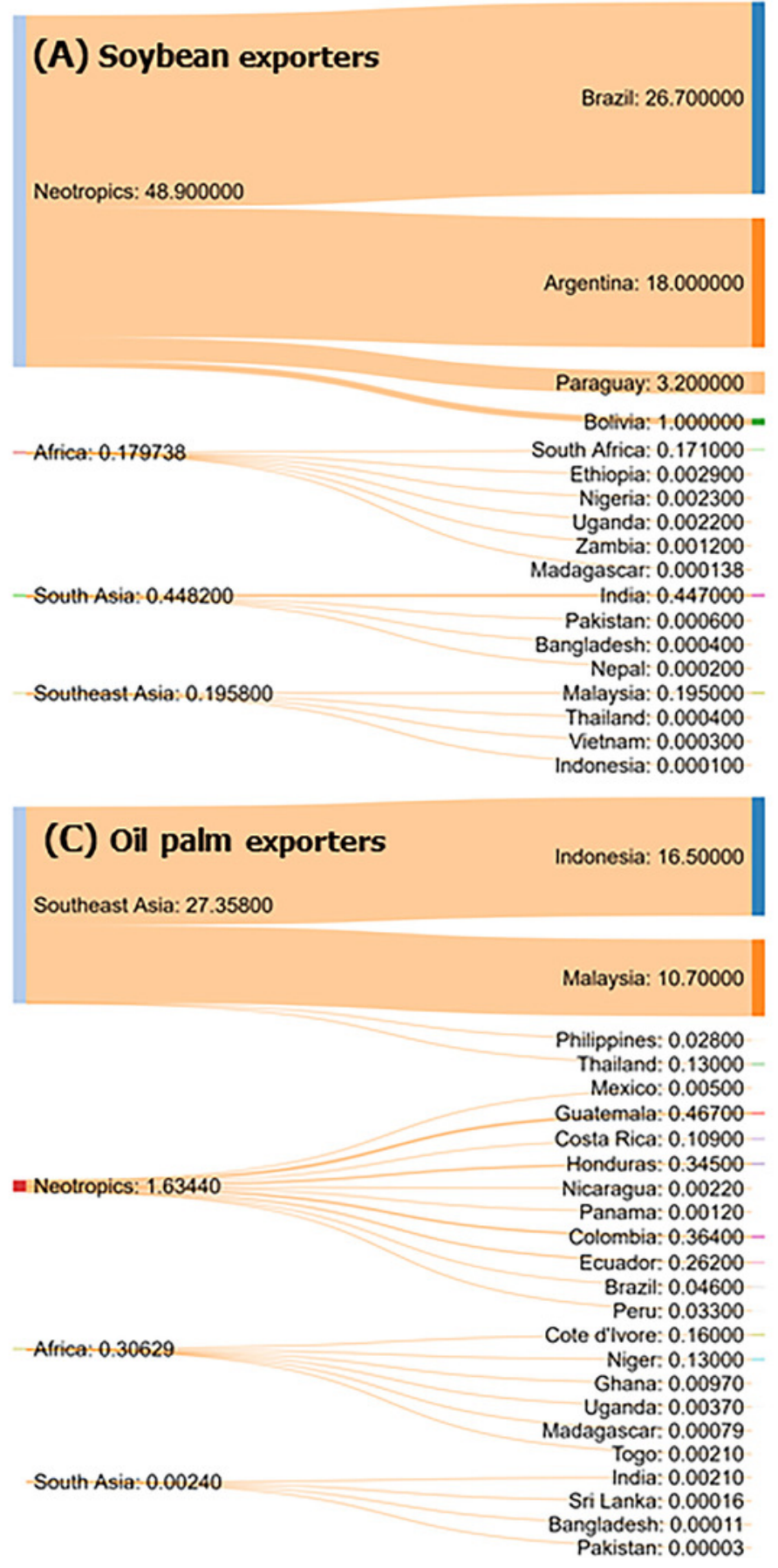

\section{(B) Soybean importers}

China: 18.711000

Neotropics: 26.900000

India: 2.803700

Netherlands: 2.000000

Vietnam: 1.800000

Spain: 1.600000

US: 0.093500

Japan: 0.054000

South Asia: 0.225000

Southeast Asia: 0.070000

Canada: 0.022000

Korea, R: 0.042000

France: 0.034000

Indonesia: 0.028000

Australia: 0.020000

Turkey: 0.005000

Italy: 0.004000

Mauritius: 0.000138

\section{(D) oil palm importers}

India: 5.507500

Southeast Asia: 11.643000

China: 3.400000

US: 1.200200

Italy: 0.955000

-Africa: 0.050849

Germany: 0.797000

ENeotropics: 0.225500

Indonesia: 0.015000

South Africa: 0.002000

Switzerland: 0.000794

France: 0.000455

UK: 0.000400

Brazil: 0.041000 


\section{Figure 7}

Trade flow diagrams for the top exporter and importer countries of four commodities that resulted in permanent deforestation in each primate-range region in 2016. Natural rubber $(A, B)$ and beef $(C, D)$.

Numbers on the flow diagrams indicate the amount in US\$ bn of trade for each country. For exports and imports, the trade flows show on the left the accumulated US\$ bn for each region and for the countries involved. The width of the connecting flows is proportional to the value exported or imported. 

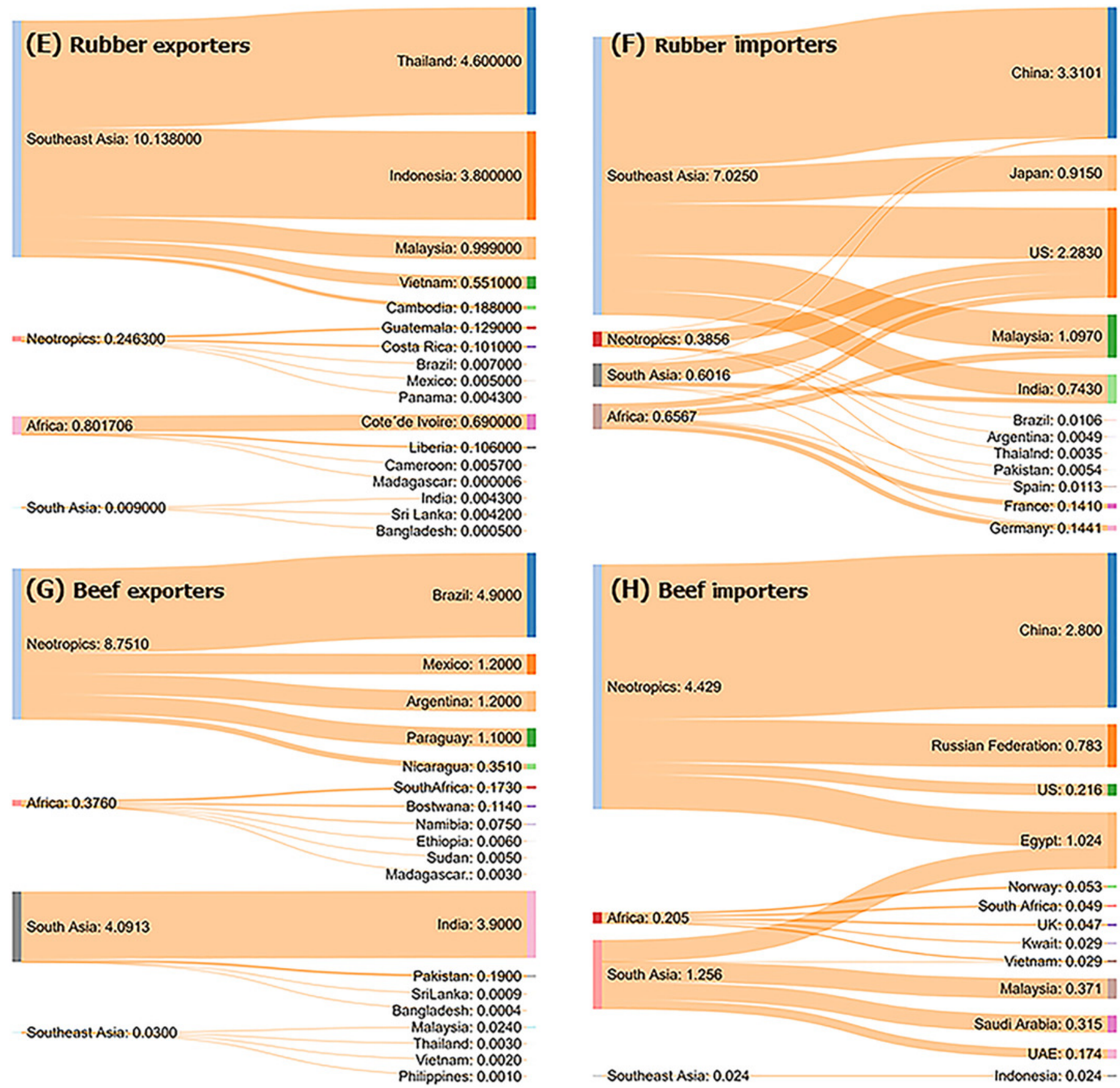

\section{(H) Beef importers}

China: 2.800

Neotropics: 4.429

Russian Federation: 0.783

US: 0.216 日

Egypt: 1.024

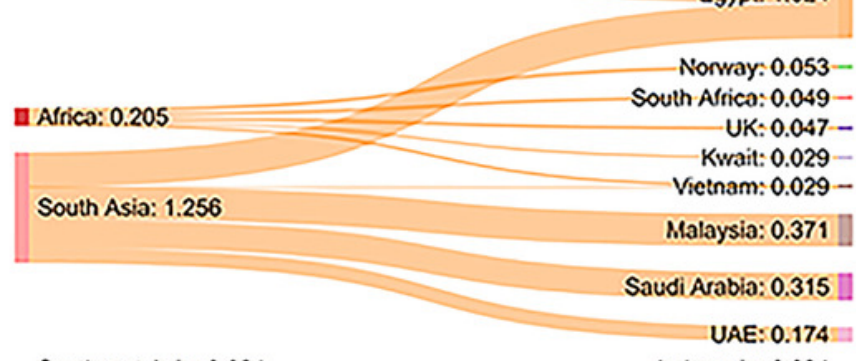




\section{Figure 8}

Photos of selected forest-risk commodities in primate range regions.

Photo credits include the following: (A) forest converted to soy fields in Brazil (photo credit: R. Butler), (B) pulp and paper plantation in Indonesia (photo credit: R. Butler) , (C) Deforestation for natural rubber production in Laos (photo credit: R. Butler). (D) Oil palm plantation in Costa Rica (photo credit: R. Butler), (E) Industrial logging in Malaysia (photo credit: W. F. Laurance.. (F) Gold mining in Peru (photo credit: R. Butler).

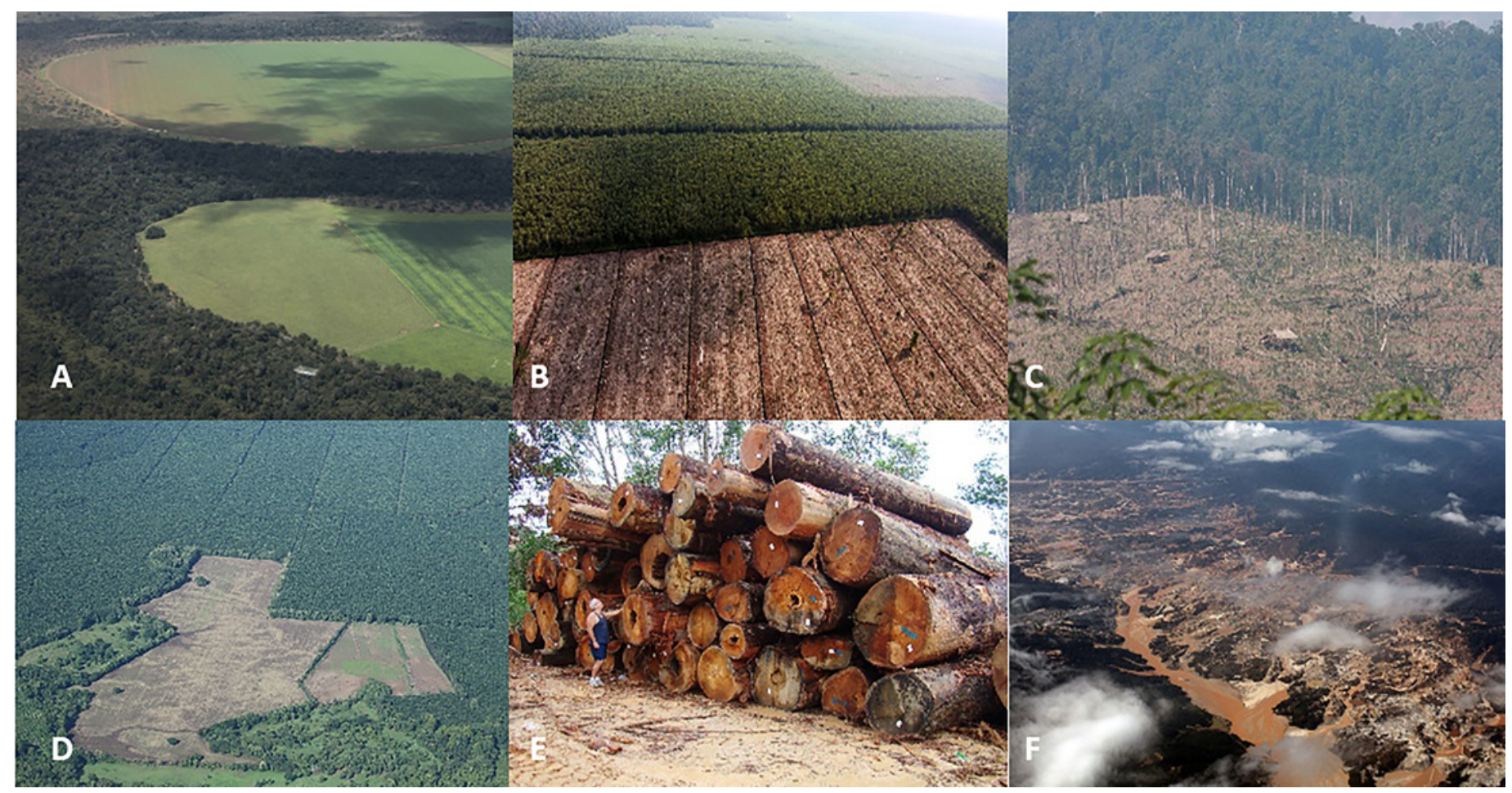


Figure 9

Growth in the export value of (A) forestry products, (B) fossil fuels, (C) metals and minerals and (D) gemstones and pearls in primate-range regions between 2000 and 2016.
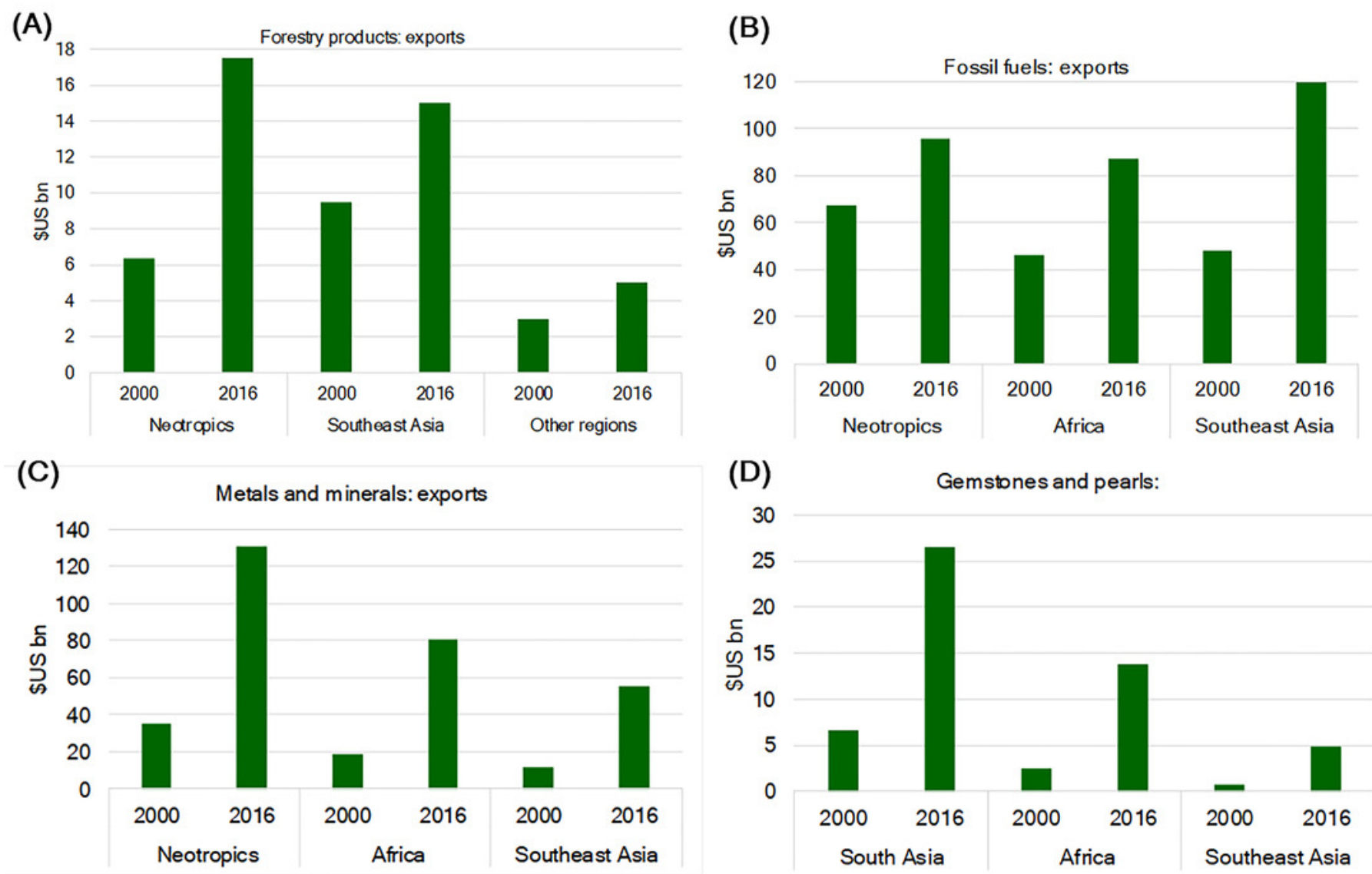


\section{Figure 10}

Trade flow diagrams of four commodities for the top exporter and importer countries and primate range regions that resulted in forest degradation in 2016 . Forestry products $(A, B)$, fossil fuels (C, D).

We show only the top exporting and importing countries in each region. Numbers on the flow diagrams indicate for each country, the amount in US\$ bn involved in trade. For exports and imports the trade flows also show on the left the accumulated US\$ bn for each region and for the countries involved. The width of the connecting flows is proportional to the value exported or imported. 


\section{(A) Forestry products exporters}

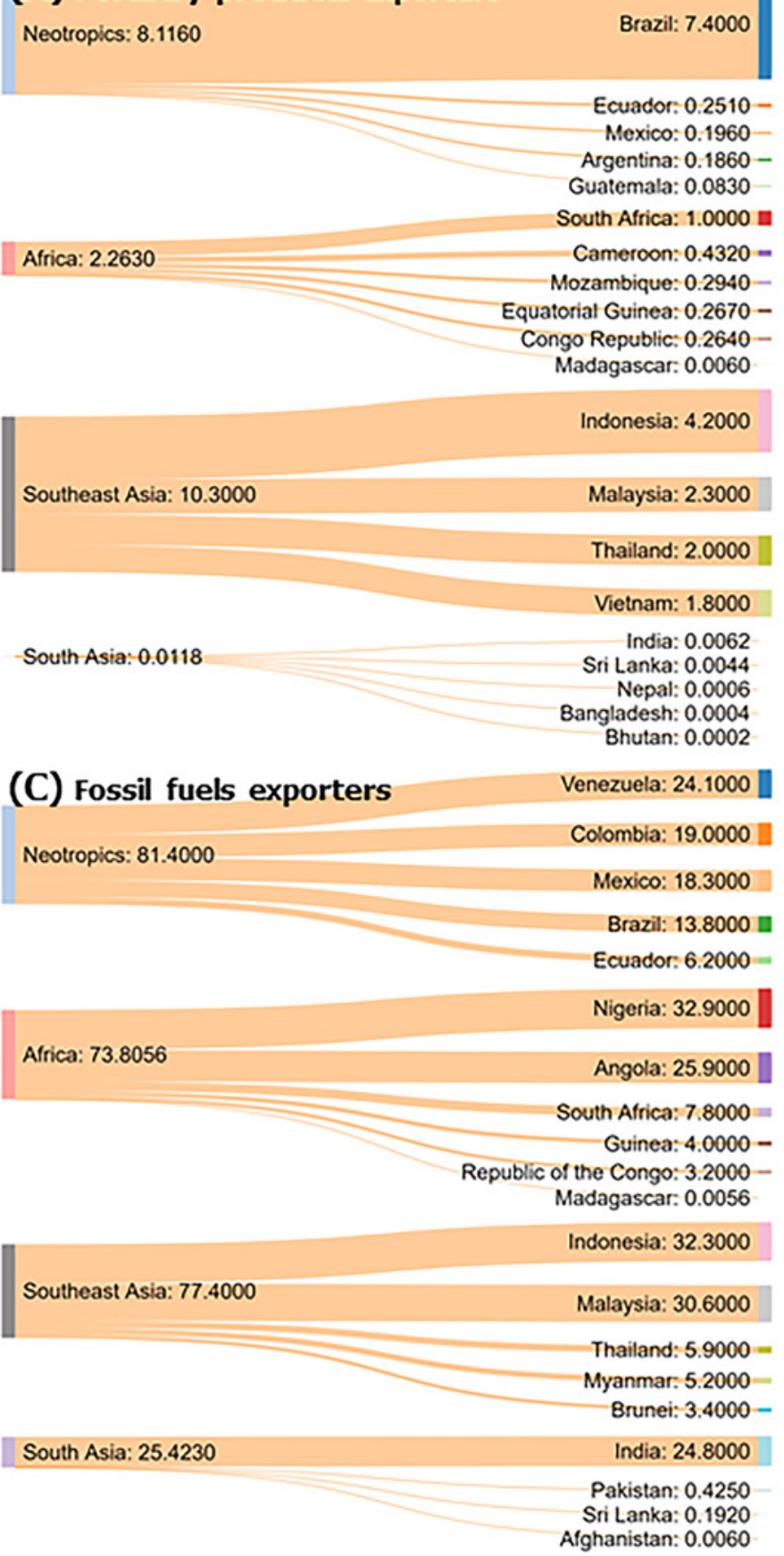

\section{(B) Forestry products importers}
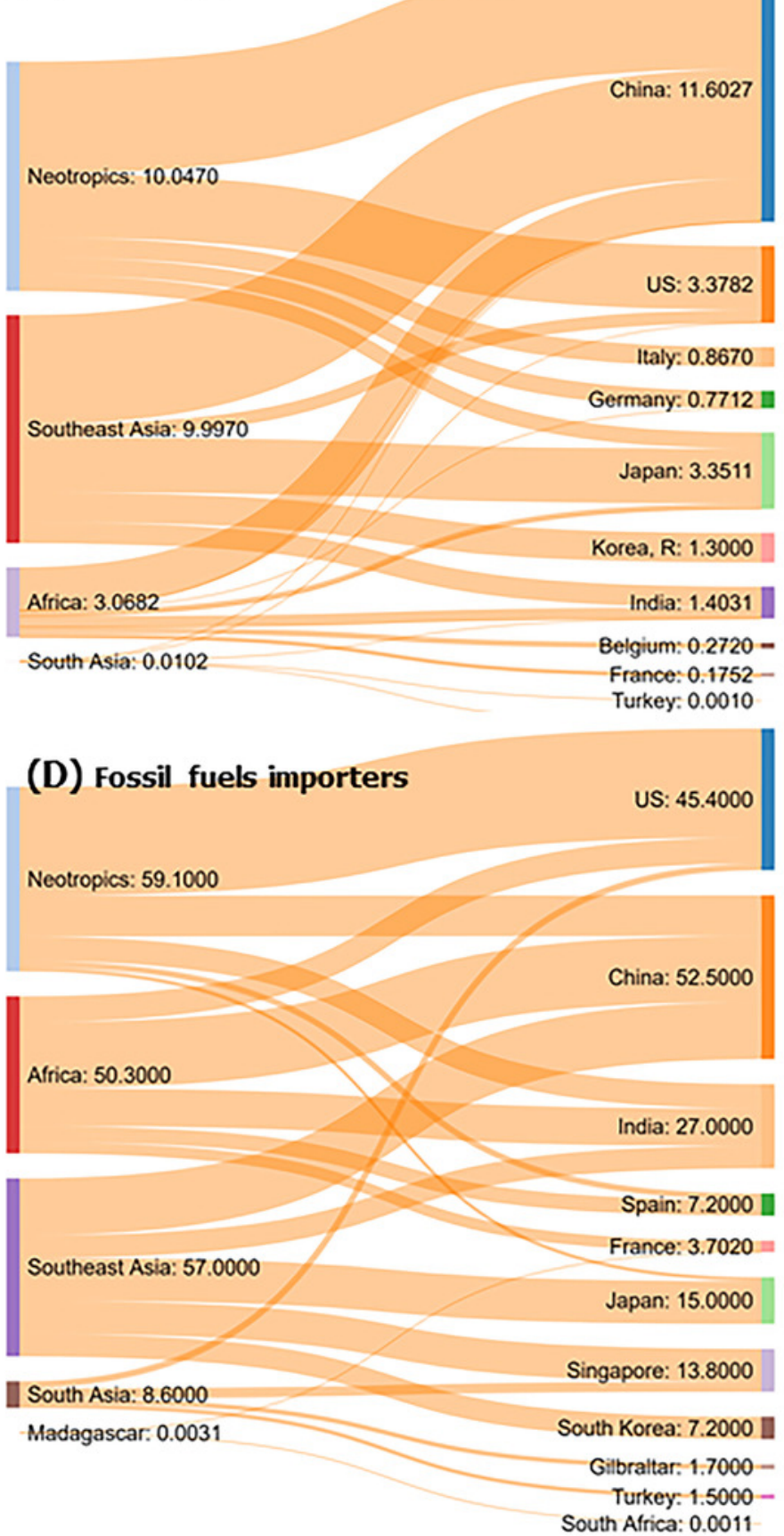


\section{Figure 11}

Trade flow diagrams of four commodities for the top exporter and importer countries in primate range regions that resulted in forest degradation in 2016. Metals and minerals $(A, B)$ and gemstones and pearls $(C, D)$.

We show only the top exporting and importing countries in each region. Numbers on the flow diagrams indicate for each country, the amount in US\$ bn involved in trade. For exports and imports the trade flows also show on the left the accumulated US\$ bn for each region and for the countries involved. The width of the connecting flows is proportional to the value exported or imported. 
(A) Metals/minerals exporters

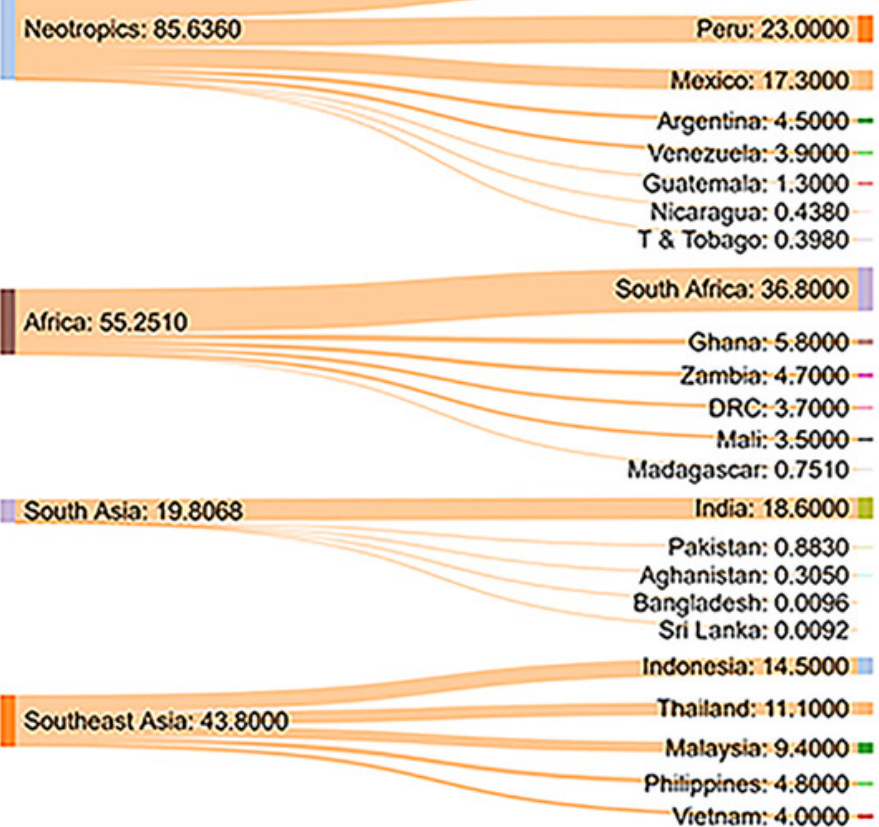

\section{(C) Gemstones and pearls exporters}

South Asia: 26.588

India: 26.400

Stri Lanka: 0.180

Pakistan: 0.005

Alghanistan: 0.003

\begin{tabular}{|rr|}
\hline Africa: 13.397 & Bostwana: 7.200 \\
& South Africa: 2.900 \\
& Angola: 1.900 \\
& Namibia: $1: 100$ \\
& Tanzania: $0.272-$ \\
\hline Southeast Asia: 3.777 & Madagascar: 0.025 \\
& Thailand: 3.600 \\
\hline Neotroplcs: 1.476 & Indonesia: 0.084 \\
& Malaysia: 0.058 \\
& Myanmar: 0.035 \\
\hline & Panama: $0.738-$ \\
& Belize: $0.314-$ \\
& Colombia: $0.257-$ \\
& Brazil: $0.164-$ \\
& Guvana: 0.003
\end{tabular}

(B) Metals/minerals importers

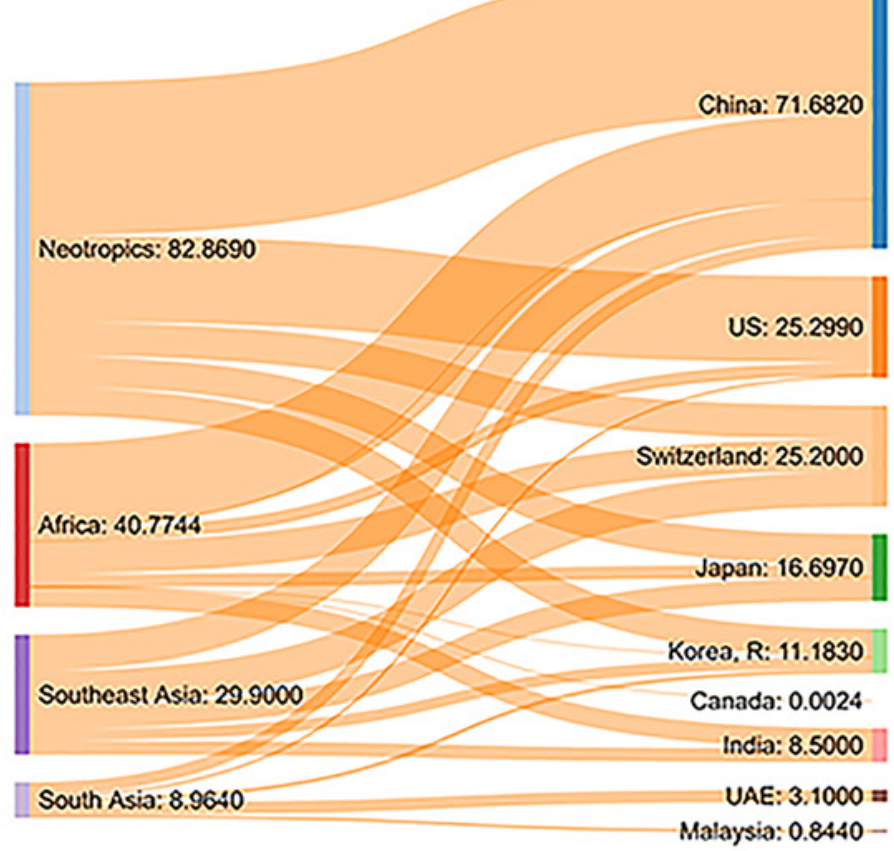

(D) Gemstones and pearls importers

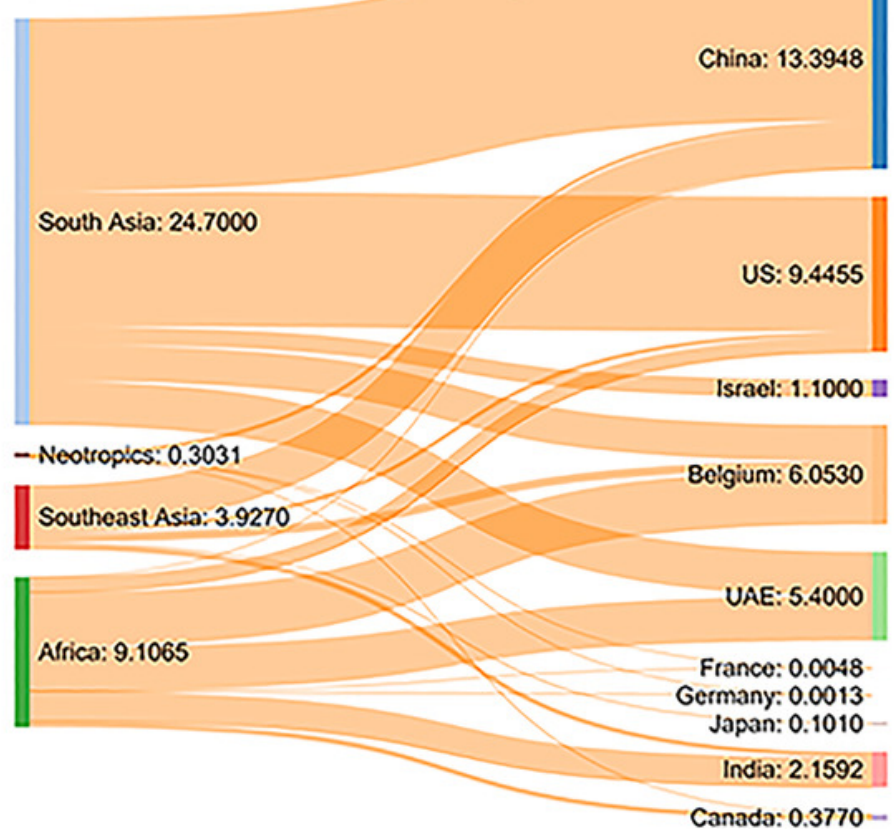


Figure 12

A) Top 10 primate range exporter countries and (B) top 10 importer countries of forestrisk commodities in 2016.

These 10 exporting countries comprise all or part of the ranges of some 250 primate species (Table S5).

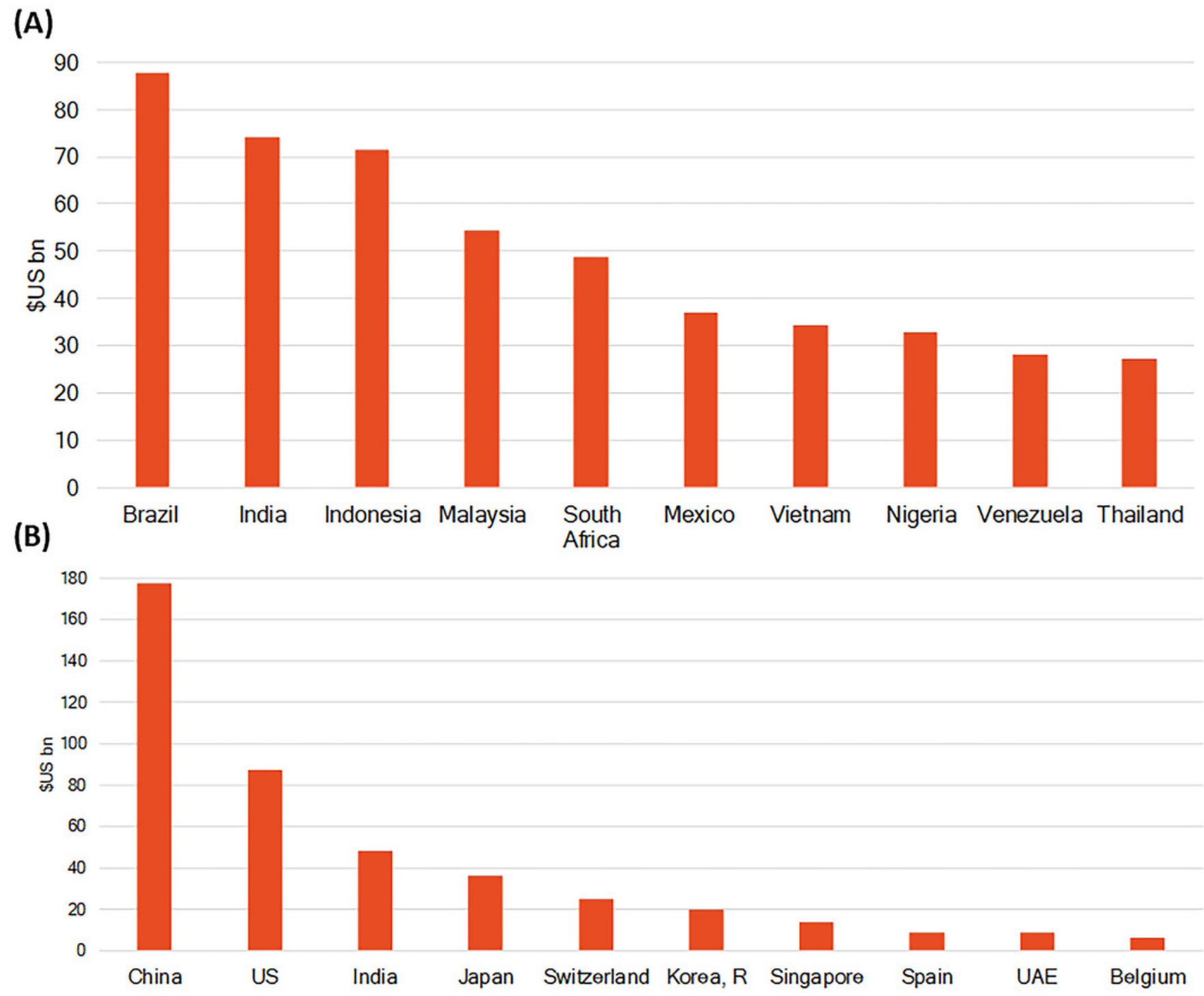




\section{Figure 13}

(A) Estimated revenues generated by exports of natural-resource commodities by nations in primate-range regions in 2016. (B) Average percent of primate species threatened and GDPPC US\$10,000 for countries in primate range regions in 2016.

The numbers in parenthesis next to the name of each region refer to the number of countries involved in each GDPPC class. 


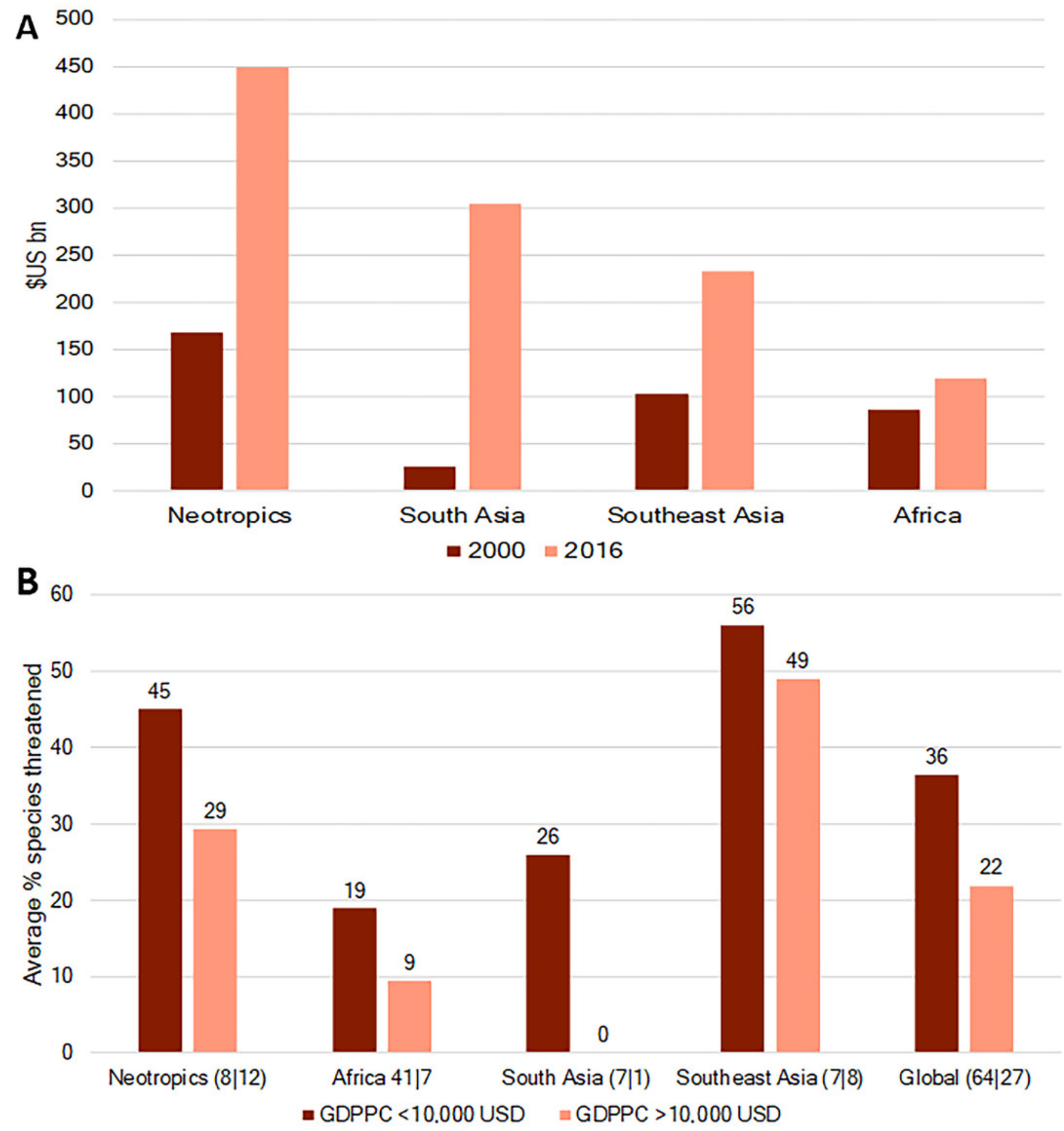




\section{Figure 14}

Percent of primate species currently threatened with extinction(2016) and the percent projected to be threatened with extinction due to commodity driven land use changes by 2050 and 2100 under a business-as-usual scenario (RCP 4.5 SSP-2).

Data are presented only for the top 15 primate richest countries in the world. SeeTable S8 for the projected fraction of primate species threatened with extinction in 61 primate habitat country's under all six future scenarios and Table S9 for the contribution of each of the 10 human land use types to the total number of species threatened with extinction.

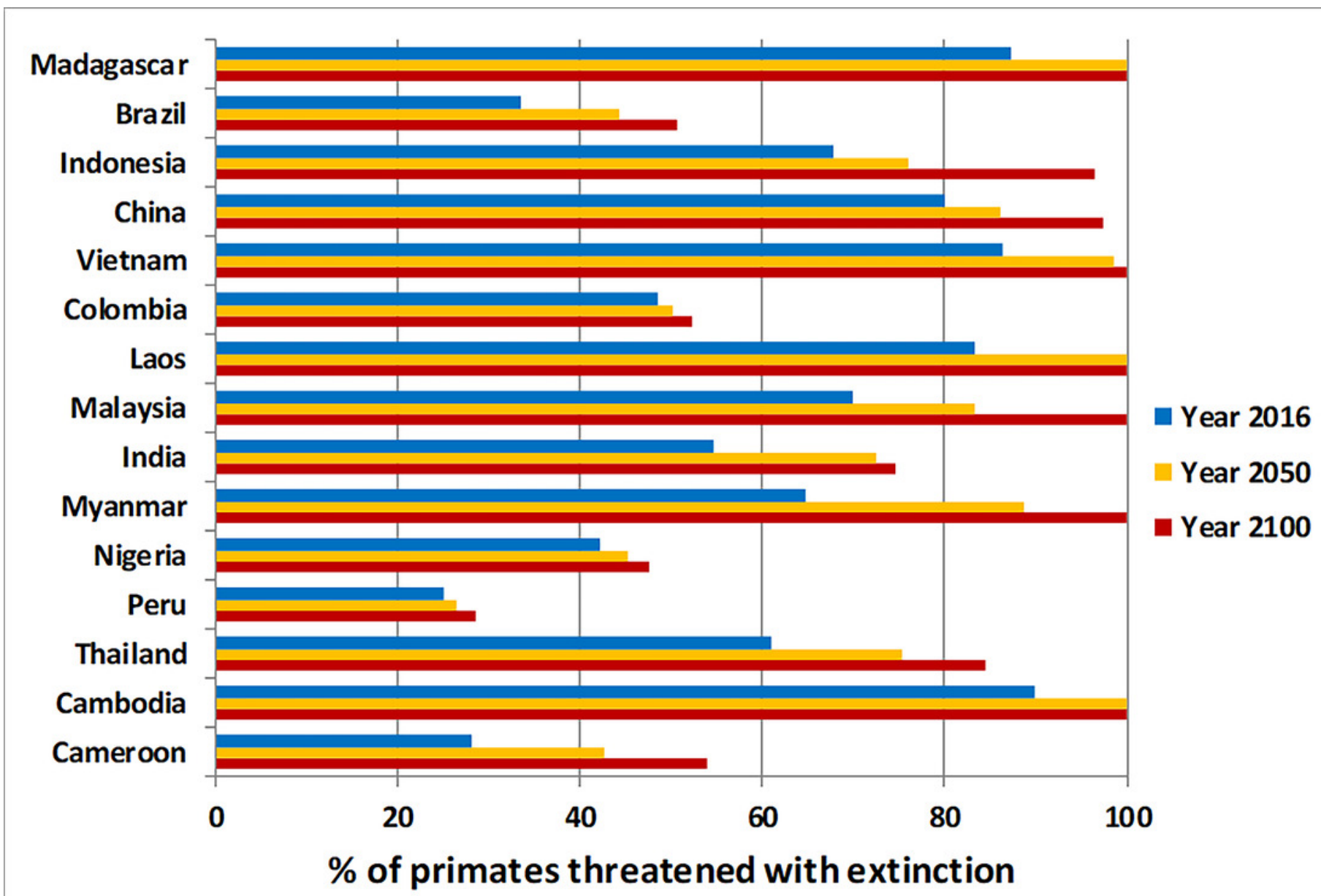




\section{Figure 15}

(A) Food Security Index and (B) GDPPC in exporting and importing countries involved in forest-risk commodities trade.

We compare the average value of the Food Security Index (FSI: 0 lowest to 100 highest) between top commodity exporting primate-range countries and top commodity importing countries in 2016. We also compare the average GDPPC for 2016 for the top primate-range commodity exporting countries and the top importer countries in 2016. 
(A) Average Food Security Index 2018

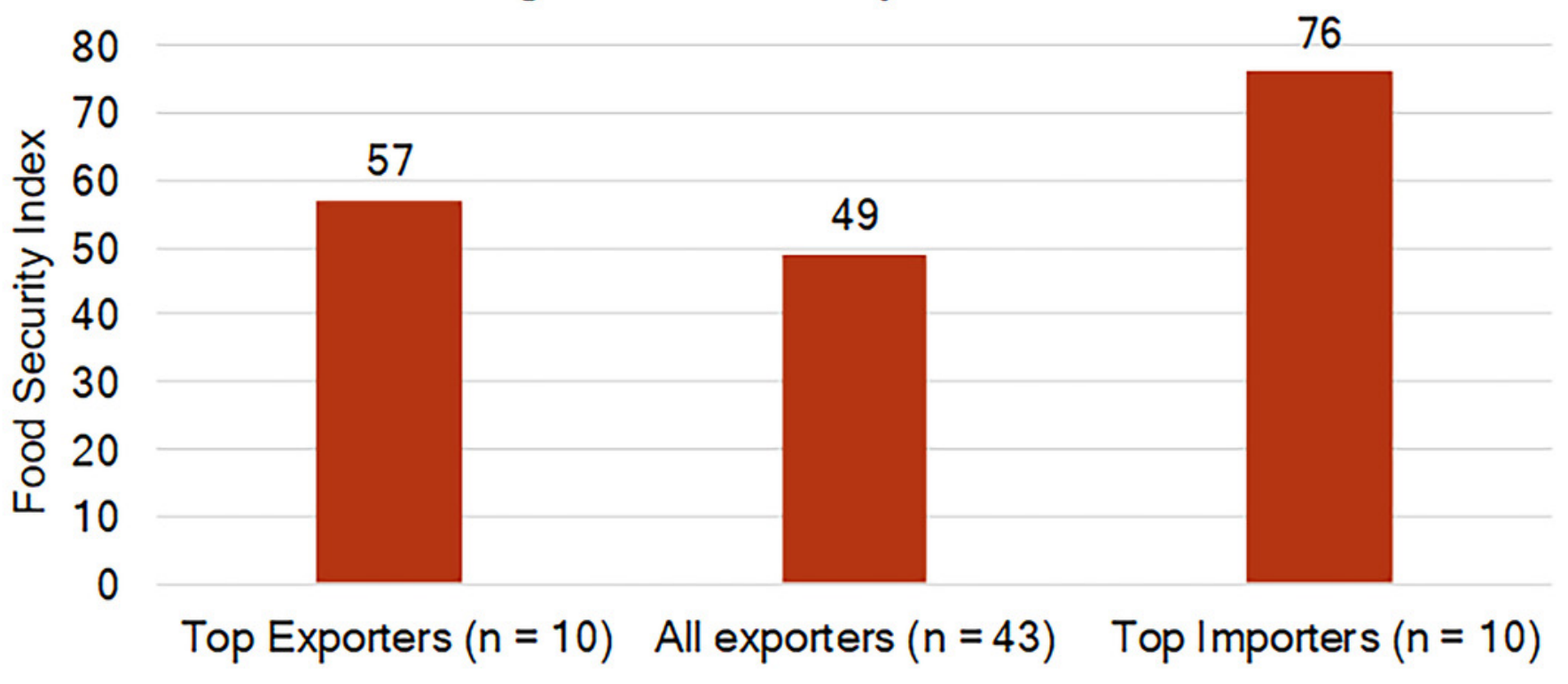

(B)

Average 2017 GDPPC (\$US)

$\$ 40,000$

$\$ 30,000$

$\stackrel{\leftrightarrow}{\supset} \$ 20,000$

$\$ 10,000$

$\$ 12,883$

\$o

$\$ 9,310$
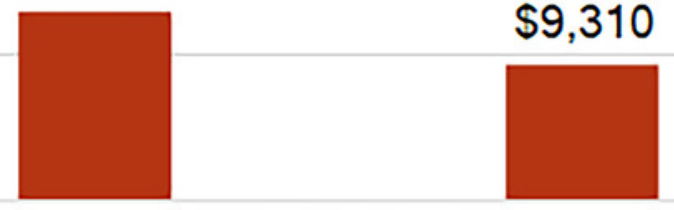

$\$ 39,108$

Top Exporters $(n=10)$ All exporters $(n=43)$ Top Importers $(n=10)$ 


\section{Figure 16}

Figure 16. Photos of selected primate species impacted by forest loss and degradation resulting from production of forest-risk commodities. Also shown is their IUCN conservation status.

Photo credits include the following: (A) Bornean orangutan (Pongo pygameus), Borneo.

Status: CR (photo credit: R. Butler), (B) Western gorilla (Gorilla gorilla), Gabon. Status: CR (photo credit: R. Butler), (C) Indochinese Lutung ( Trachypithecus germaini ), Cambodia. Status: EN (photo credit: R. Butler), (D) white-headed langur (Trachypithecus poliocephalus, China. Status: CR (photo credit P. A. Garber), (E) Black-and-white ruffed lemur (Varecia variegata), Madagascar. Status: CR (photo credit: S. Johnson), (F) male black howler monkey (Alouatta pigra), Mexico. Status: EN (photo credit: S. Van Belle). EN= endangered, $\mathrm{CR}=$ critically endangered.

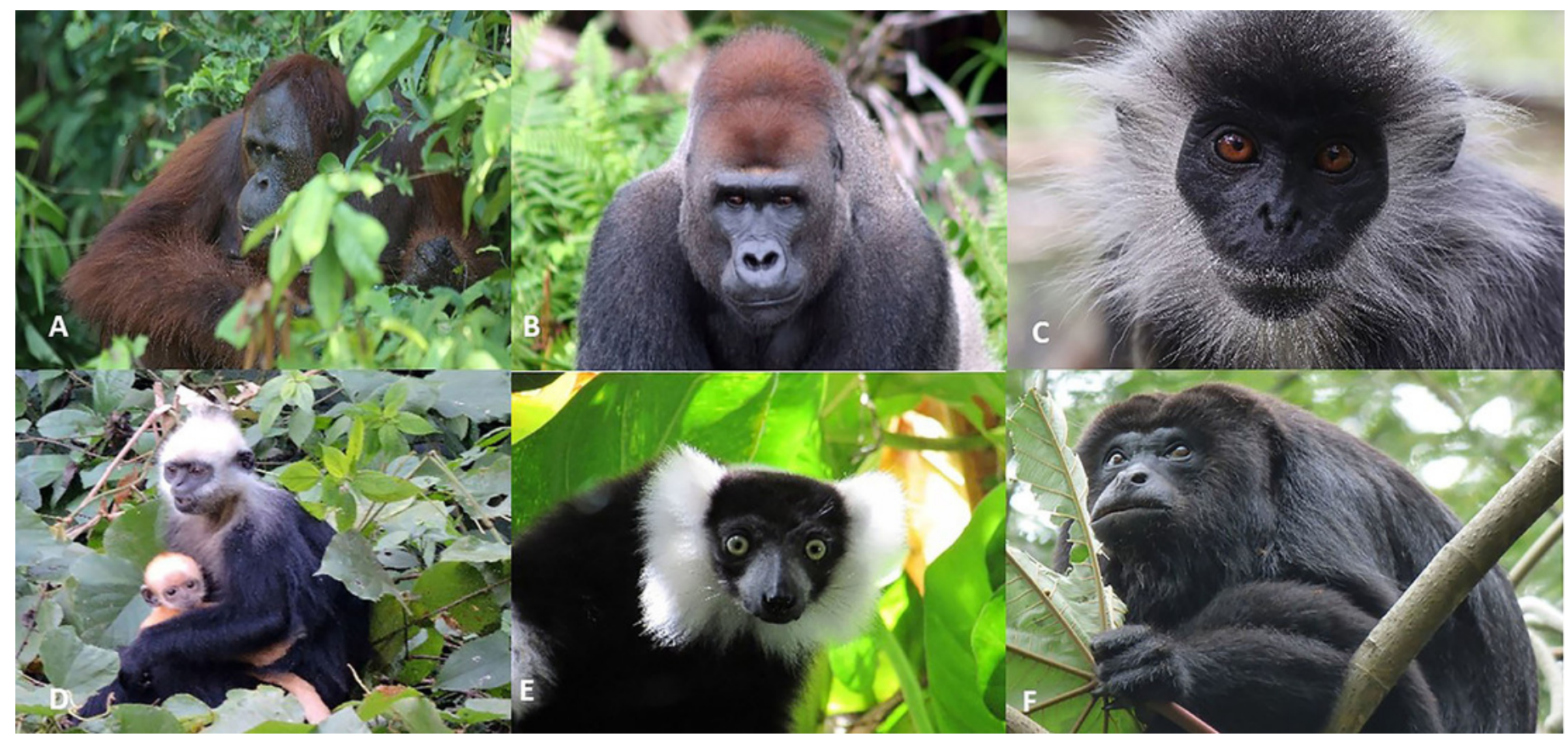




\section{Figure 17}

\section{Diagram summarizing key aspects of international commodities trade and primate} conservation.

\section{Key challenges for global primate conservation}

Principaldrivers

- Destructive patterns of human land use

- International trade of commodities

- Human colonization of frontier forests

- Increased bushmeat hunting

- Increased legal and illegal primate trade

- Spread of infectious diseases

- Increased human-primate conflict

- Human-induced climate change

\section{Possiblemitigatingmeasures}

- Limiting impact of industrial agriculture and extractive industries on primate habitats.

On-going processes

Habitat lossand degradation

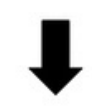

Population declines

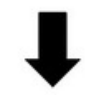

Increased extinction risk
- Promoting sustainable intensification of agriculture on cleared lands and ecofriendly approaches to agriculture.

- Greening international commosdities trade. Comsuption tax on products that cause environmental damage and loss of biodiversity. Create an international body with publicand private sector funds to restore areas of natural forest.

- Changing consumer food habits: e.g. use less oil seed, eating less meat (beef), diminish use of tropical timber, fossil fuels, metals, minerals and gemstones from the tropics.

- Expanding and connecting áreas of natural hábitat and protected Parks and apply population recovery measures where needed.

- Regulating environmental destruction and the expansión of infrastructure resulting from the Belt and Road Initiative

- Local human population: ensuring food security and income to reduce poverty and improve the health and well-being of local human communities. 